\title{
Geographic Distribution of Chagas Disease Vectors in Brazil Based on Ecological Niche Modeling
}

\author{
Rodrigo Gurgel-Gonçalves, ${ }^{1}$ Cléber Galvão, ${ }^{2}$ Jane Costa, ${ }^{3}$ and A. Townsend Peterson ${ }^{4}$ \\ ${ }^{1}$ Laboratório de Parasitologia Médica e Biologia de Vetores, Área de Patologia, Faculdade de Medicina, Universidade de Brasília, \\ Campus Universitário Darcy Ribeiro, 70904-970 Brasília, DF, Brazil \\ ${ }^{2}$ Laboratório Nacional e Internacional de Referência em Taxonomia de Triatomíneos, Instituto Oswaldo Cruz, FIOCRUZ, \\ 21045-900 Rio de Janeiro, RJ, Brazil \\ ${ }^{3}$ Laboratório de Biodiversidade Entomológica, Instituto Oswaldo Cruz, FIOCRUZ, 21045-900 Rio de Janeiro, RJ, Brazil \\ ${ }^{4}$ Biodiversity Institute, The University of Kansas, Lawrence, KS 66045-7593, USA
}

Correspondence should be addressed to Rodrigo Gurgel-Gonçalves, rgurgel@unb.br

Received 16 July 2011; Accepted 23 October 2011

Academic Editor: Maria Goreti Rosa-Freitas

Copyright (c) 2012 Rodrigo Gurgel-Gonçalves et al. This is an open access article distributed under the Creative Commons Attribution License, which permits unrestricted use, distribution, and reproduction in any medium, provided the original work is properly cited.

\begin{abstract}
Although Brazil was declared free from Chagas disease transmission by the domestic vector Triatoma infestans, human acute cases are still being registered based on transmission by native triatomine species. For a better understanding of transmission risk, the geographic distribution of Brazilian triatomines was analyzed. Sixteen out of 62 Brazilian species that both occur in $>20$ municipalities and present synanthropic tendencies were modeled based on their ecological niches. Panstrongylus geniculatus and $P$. megistus showed broad ecological ranges, but most of the species sort out by the biome in which they are distributed: Rhodnius pictipes and $R$. robustus in the Amazon; $R$. neglectus, Triatoma sordida, and T. costalimai in the Cerrado; $R$. nasutus, $P$. lutzi, T. brasiliensis, T. pseudomaculata, T. melanocephala, and T. petrocchiae in the Caatinga; T. rubrovaria in the southern pampas; T. tibiamaculata and T. vitticeps in the Atlantic Forest. Although most occurrences were recorded in open areas (Cerrado and Caatinga), our results show that all environmental conditions in the country are favorable to one or more of the species analyzed, such that almost nowhere is Chagas transmission risk negligible.
\end{abstract}

\section{Introduction}

Chagas disease or American trypanosomiasis is a chronic and potentially fatal infection caused by the protozoan Trypanosoma cruzi [1]. Contamination of mucosa by feces of blood-sucking infected insects (Hemiptera, Reduviidae, Triatominae) is the most important way of transmission, althought transmission may also occur congenitally, by blood transfusion, from organ donors, and orally, via ingestion of food contaminated with T. cruzi. No vaccines, or effective antiparasitic treatments are available to cure the chronic phase of Chagas disease, so control of domiciliated vectors is the main strategy to prevent human infection [2-4]. Chagas disease, originally restricted to Latin America, is now becoming a global public health concern in nonendemic areas owing to human migrations to developed countries [5].
In Brazil, the Chagas disease national control program was implemented in 1975-1983, when Triatoma infestans infested domiciles of 700 municipalities in 12 Brazilian states [6]. At that time, $4.2 \%$ of the Brazilian population was estimated to be infected and around 100,000 new cases were recorded per year [7]. In 1991, Brazil joined the Southern Cone Initiative, an international consortium with the main objective of reducing vectorial transmission through insecticide spraying against $T$. infestans. After 10 years of effort, the project had a crucial impact on Chagas disease transmission in the Southern Cone countries, resulting in a $94 \%$ reduction of disease incidence [8]. Subsequent initiatives were also launched in the Andean region, Central America, and Amazonia [9]. The total prevalence of Chagas disease was reduced from $>16$ million to 8 million people, estimated in 2005 [10] and numbers of deaths were also 
reduced drastically [11]. In 2006, the Intergovernmental Initiative of Southern Cone, OMS, certified Brazil as free of vectorial transmission by T. infestans $[12,13]$. In Brazil, the current estimate is that 1.9 million people are infected [10], much lower than the 6 million estimated in the 1980s [8].

The last Brazilian seroprevalence inquiry was carried out in 2001-2008, including 104,954 children, in which only 32 cases were detected, indicating significant reduction of transmission in recent years [14]. Nonetheless, acute cases of Chagas disease are presently being recorded in Brazil, mainly in the Amazon region [15]. In those cases, transmission involves either sylvatic vectors invading houses, food contamination or domestic/peridomestic populations of native triatomine species. The occurrence of those triatomines represents a great difficulty for the achievements via vectorial control [16-18].

Currently, in the subfamily Triatominae, 142 species are grouped in 18 genera and five tribes [19-24]. Studies of the geographic distribution of these species are crucial for understanding epidemiologic aspects of Trypanosoma cruzi transmission, and must be considered to orient control and monitoring of the disease. The study of the potential geographic distribution of important vector species is crucial for understanding geographic dimensions of risk transmission of the disease. In this context, ecologic niche modeling (ENM) is a tool that permits exploration of geographic and ecologic phenomena based on known occurrences of the species $[25,26]$. ENM has been applied broadly to understanding aspects of Chagas disease transmission in the last decade, including characterization of the niches of vector species, and analysis of relationships between vector and reservoir distributions [27-37]. The objective of the present study is to analyze the geographic distributions of the triatomine species in Brazil and the factors related to their areas of occurrence. Ecologic aspects of the most important species are discussed, contributing to the knowledge of Chagas disease vectors in Brazil.

\section{Material and Methods}

2.1. Distribution Data. Distribution data of triatomine species in Brazil were obtained mainly from Lent and Wygodzinsky [38], Silveira and colleagues [6], and Carcavallo and colleagues [39]. New records were obtained from more recent studies [32, 33, 36, 37, 40-65]. We also obtained distributional data from species described after 1999 [22, 66-71]. Additionally, we analyzed triatomine records in the collections of Rodolfo Carcavallo and Herman Lent in the Laboratório Nacional e Internacional de Referência em Taxonomia de Triatomíneos, Instituto Oswaldo Cruz, FIOCRUZ. Recent information on the distribution of triatomines provided by Brazilian State Health Departments was also included.

\subsection{Ecological Niche Models}

2.2.1. Input Data. We compiled 3563 records of triatomines in Brazil that could be referenced to geograph- ic coordinates with a reasonable degree of confidence (i.e., with an uncertainty of $\leq 5 \mathrm{~km}$, to a precision of $\left.\pm 0.01^{\circ}\right)$. All records were georeferenced based on consultation of http://www.fallingrain.com/world/ and http:// www.ibge.gov.br/. Eliminating duplicate records at this spatial resolution and removing a few records that presented obvious errors of georeferencing or identification, 3223 records remained, which documented occurrence of 62 triatomine species in the country. These data were organized in spreadsheets for analysis.

We set an occurrence data sample size criterion of 20 unique latitude-longitude points per species as a minimum to permit robust ENM development, based on previous analyses $[72,73]$ and extensive experience with such applications. This threshold left a total of 17 species: Panstrongylus megistus, P. lutzi, P. geniculatus, Triatoma pseudomaculata, T. rubrovaria, T. sordida, T. tibiamaculata, T. petrocchiae, T. brasiliensis, T. melanocephala, T. costalimai, T. vitticeps, Psammolestes tertius, Rhodnius neglectus, $R$. nasutus, $R$. pictipes, and $R$. robustus. In view of the exclusively sylvatic nature of the species Ps. tertius [63], we did not include this species in subsequent analyses. Barve and colleagues [74] recently recommended that niche and distribution models be calibrated across areas coinciding with the dispersal area (termed "M" by them) in the Biotic-Abiotic-Mobility (BAM) framework for understanding species geographic distributions [75], an assertion with which we concur amply. As essentially all of the species in this study have broad geographic distributions, we are comfortable with a relatively broad definition of $\mathbf{M}$. However, a modification of the BAM framework for definition of calibration areas is based on considering the area that was actually sampled to produce the occurrence data for a study, which we can term S. Because both $\mathbf{M}$ and $\mathbf{S}$ determine the area that can possibly produce a presence record, albeit for very different reasons, and because our occurrence data came only from the extent of Brazil, we define our calibration area as $\mathbf{M} \cap \mathbf{S}$, which in this case is the whole extent of Brazil.

To characterize environmental variation across Brazil, we used two very different environmental datasets: multitemporal remotely sensed imagery and climatic data. The multitemporal (monthly) normalized difference vegetation index values (NDVI, a "greenness" index) were drawn from the Advanced Very High Resolution Radiometer satellite. These datasets have a native spatial resolution of $\sim 1 \mathrm{~km}$. The monthly nature of these greenness indices (April 1992March 1993) effectively provides a detailed view of vegetation phenology across the country, which has proved quite useful and informative in recent analyses [76]. The years 1992-1993 coincide well with the temporal provenance of much of the occurrence data.

The second environmental dataset consisted of "bioclimatic" variables characterizing climates during 1950-2000 drawn from the WorldClim data archive [77]. To avoid the confounding effects of calibrating models in an overly dimensional environmental space [78], we chose only a subset of the 19 "bioclimatic" variables in the climatic data 
archive: annual mean temperature, mean diurnal range, maximum temperature of warmest month, minimum temperature of coldest month, annual precipitation, precipitation of wettest month, and precipitation of driest month. Both environmental datasets were resampled to $0.0417^{\circ}$ spatial resolution for analysis, to match the approximate precision of the georeferencing of the occurrence data.

2.2.2. Modeling Strategy and Methods. Different algorithms have different strengths and weaknesses in particular situations [79], which makes the choice of method an important consideration. In view of the particular characteristics of this study - that is, the area of interest is the area sampled, with no need for transfer of models over broader or other landscapes-Maxent appeared to be an excellent choice. Although recent comparative studies identifying Maxent as the "best" algorithm [80] are oversimplifications, our experience and analysis [81] indicate that it is indeed the ideal choice for this particular study. We used default parameters, except that we chose a random seed, with 5 replicate analyses based on bootstrap subsampling; we used the median output grids as the best hypothesis of potential range and imported them into ArcGIS 10 as floating point grids.

For model results, for each combination of species with environmental dataset, we thresholded raw Maxent output independently. To emphasize the fact that omission error takes considerable precedence over commission error in niche modeling applications, we used a modified version of the least training presence thresholding approach [82] that takes into account the fact that some degree of error may exist in a dataset (otherwise, model predictions thresholded using this approach will be broadened artificially by error). Specifically, we estimated $E$, the expected amount of meaningful error in occurrence data [81] at 5\%, and thresholded models at the suitability level that included $100-E=95 \%$ of the model calibration data to produce binary models summarizing likely presence and absence over the landscape. Finally, we combined the models from the two environmental datasets by multiplying them-this step had the effect of retaining areas as suitable only if they were judged as suitable by models based on both the AVHRR and climatic datasets. We note that because our initial hypothesis was that all of Brazil is available to each species for potential colonization, we took no specific steps to reduce model predictions from potential to actual distributional areas.

Analyses were focused on the species diversity of broadly distributed (i.e., included within our initial list of wellsampled species) and human-disease-important triatomine species. As a result, we took the final, thresholded, and combined map for each of the 16 species listed above and summed them-given the binary nature of each of the maps, the sums yield a hypothesis of numbers of species present across Brazil. To provide a view of species' responses to environmental variation across Brazil, we plotted 1000 random points across the country, and assigned to each (1) the predicted presence or absence of each species and (2) the values of the first two principal components of the

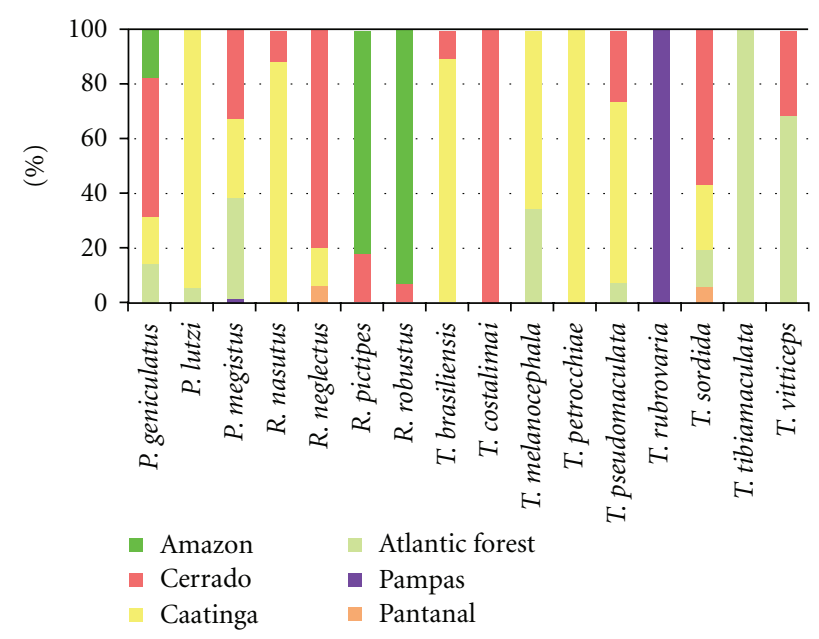

FIGURE 1: Relative occurrence of 16 species of triatomines across biomes, calculated based on proportions of known occurrences falling in each area.

bioclimatic data set, which summarize much of the variation in climatic dimensions in a readily accessible and visualizable space of two dimensions.

\section{Results}

3.1. Diversity Patterns. Sixty-two of the 142 known triatomine species have been found in Brazil (Table 1). Thirtynine out of 62 species (63\%) occur only in Brazil. The state of Bahia, in northeastern Brazil, has the largest number of species ( $25 \mathrm{spp}$.), followed by Mato Grosso (18 spp.) in the central-west, Para and Tocantins (15 spp.) in the north, and Minas Gerais (15 spp.) in the Southeast. Rio Grande do Sul is the state with the largest number of species in southern Brazil (11 spp.). Acre and Amapá are the states with the lowest number of recorded species (Table 1).

Grouping the 62 triatomine species by biome, we noted that the greatest number of species inhabits the Cerrado biome $(n=24 ; 39 \%)$, followed by the Amazon $(n=16$; $26 \%)$, Caatinga $(n=15 ; 24 \%)$, and Atlantic Forest $(n=15$; $24 \%)$. Fewer species were recorded in the Pantanal $(n=9$; $15 \%)$ and Pampas $(n=8 ; 13 \%)$ biomes. The geographic distributions of some species coincide strongly with the distribution of particular biomes, while other species (e.g., P. geniculatus and T. sordida) occurred in at least four biomes (Figure 1). Most of these species occur in open areas in the cerrado and caatinga biomes, where the majority (70\%) of occurrences were recorded.

3.2. Ecological Niche Models. We modeled the ecological niches of the 16 Brazilian triatomine species that are well sampled and present synanthropic tendencies. Of these species, P. geniculatus and P. megistus showed broad ecological and geographic distributions (Figure 2). The distributions of $R$. neglectus, T. costalimai, and T. sordida coincided with the Cerrado biome in central Brazil (Figure 3). On the other hand, distributions of $R$. nasutus, P. lutzi, 


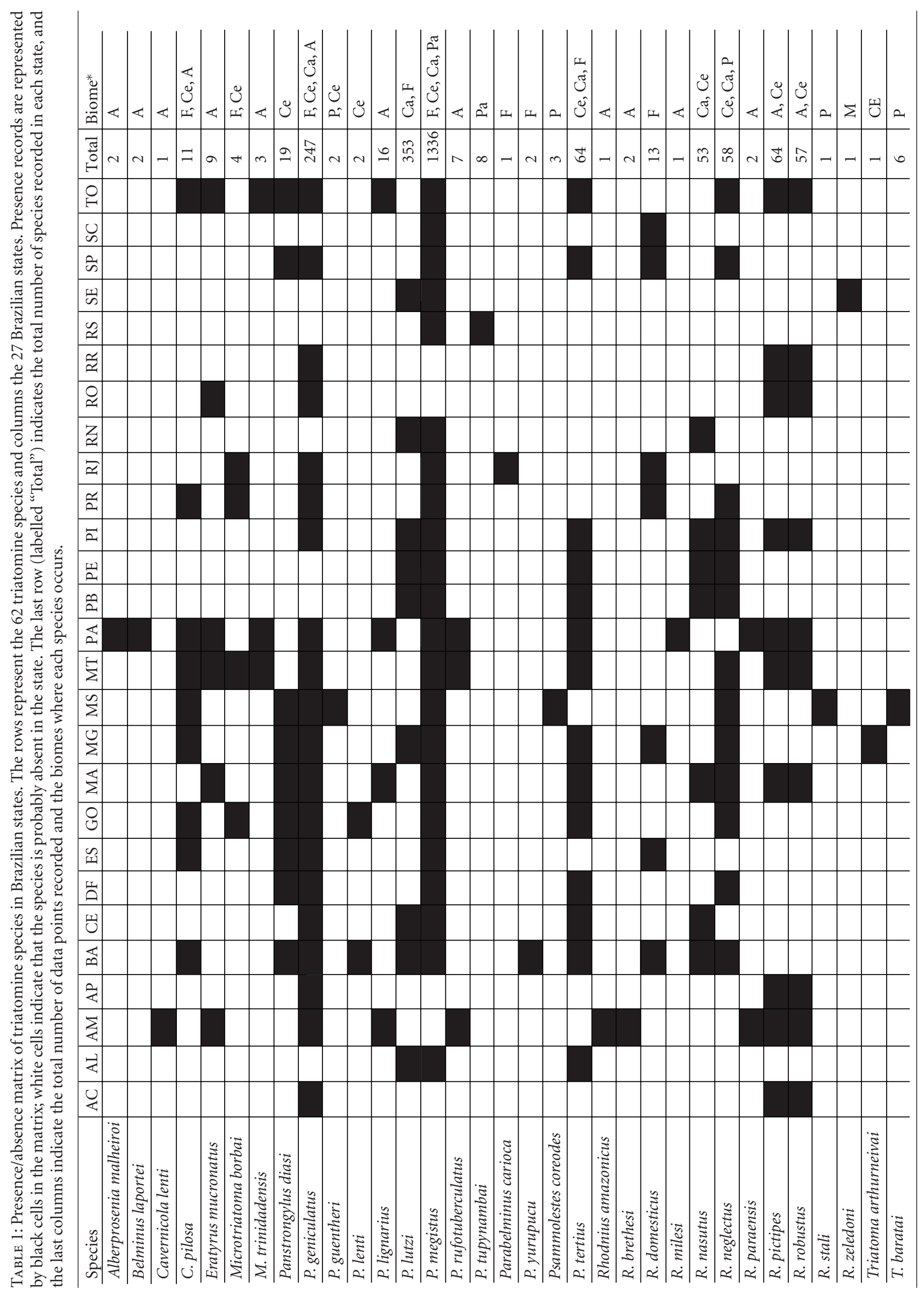




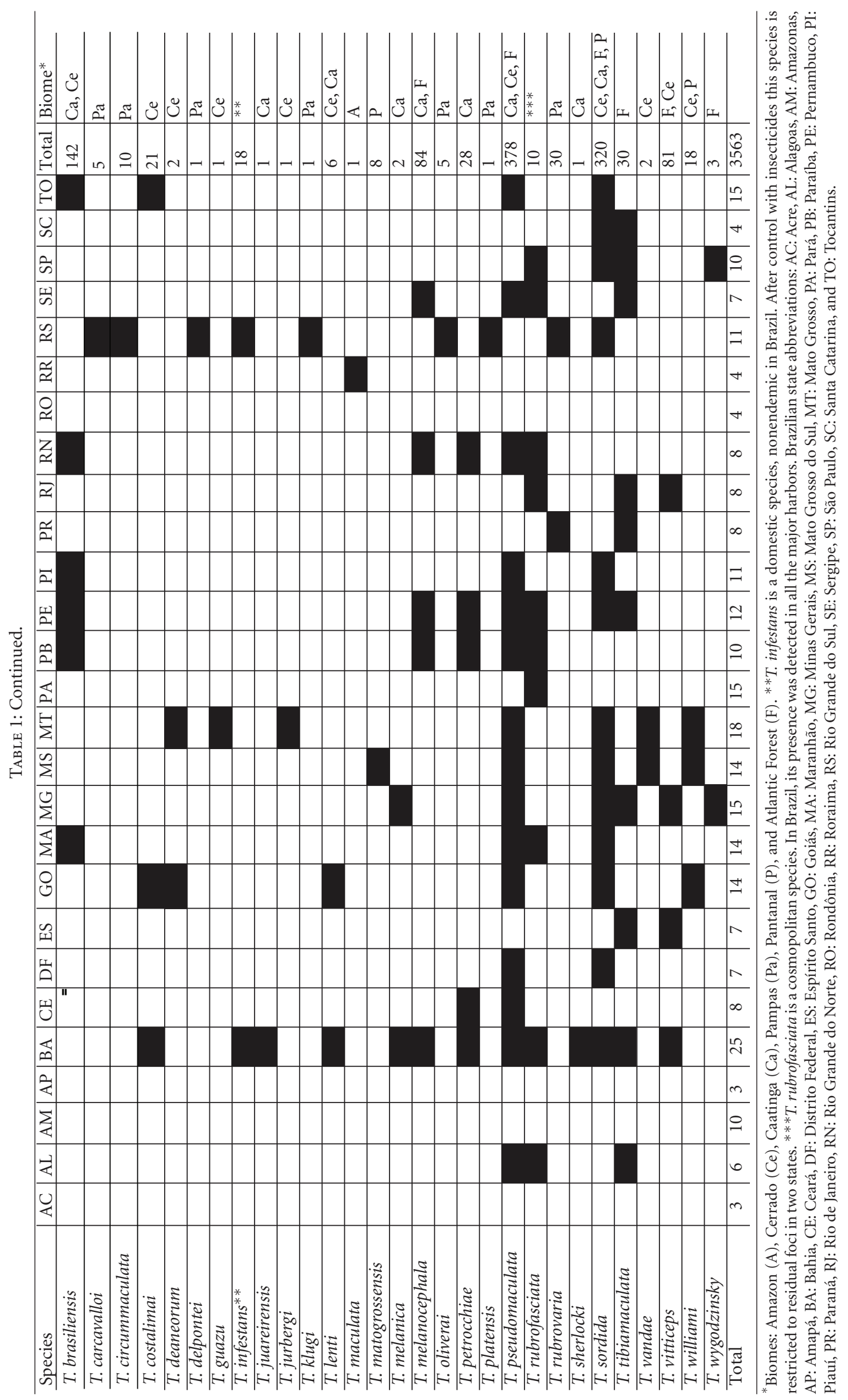




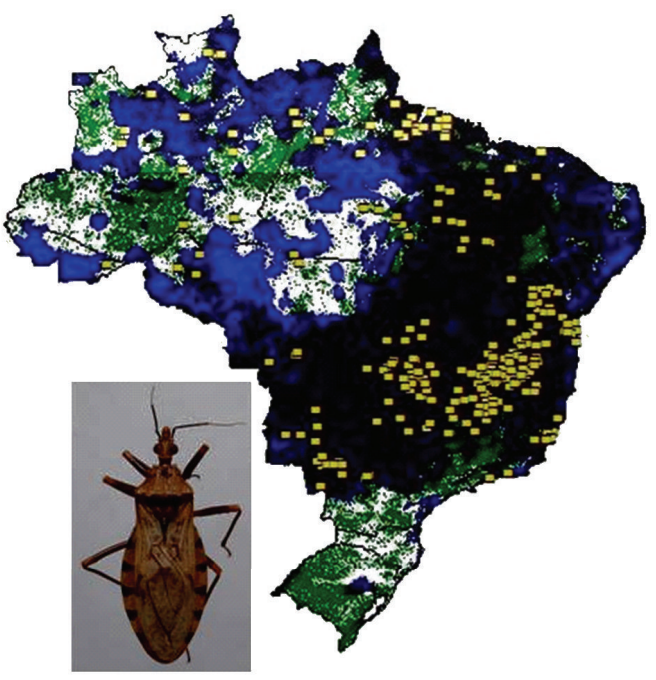

(a)

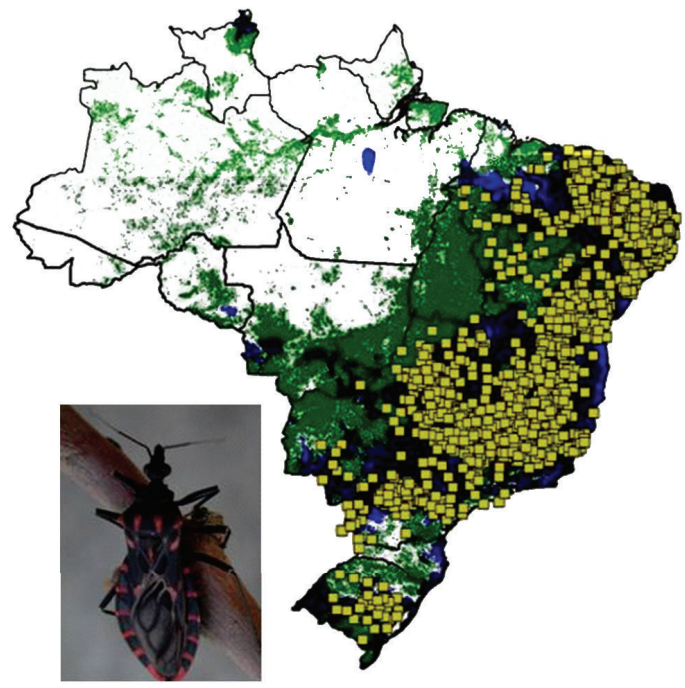

(b)

Figure 2: Ecological niche models projected as potential distributions for triatomine species with widespread distribution in Brazil. (a) Panstrongylus geniculatus and (b) P. megistus. Known occurrences of the species are shown as yellow squares, and the final consensus prediction is shown as black shading. Areas identified as suitable based on climatic grounds only are shown in blue, whereas areas identified as suitable based on normalized difference vegetation index (NDVI) only are shown in green.

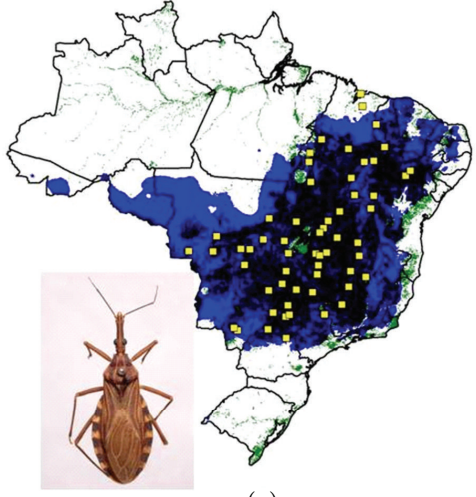

(a)

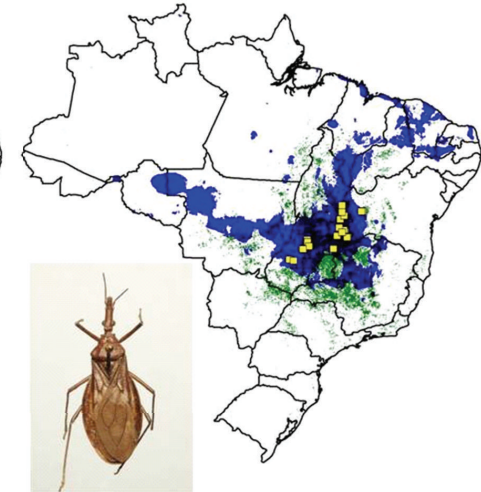

(b)

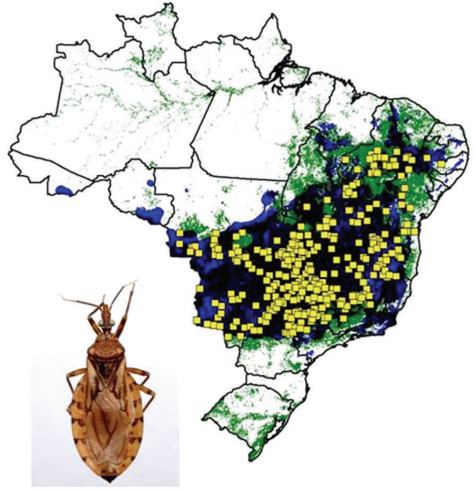

(c)

Figure 3: Ecological niche models projected as potential distributions for triatomine species in central Brazil. (a) R. neglectus, (b) T. costalimai, and (c) T. sordida.

T. brasiliensis, T. pseudomaculata, T. melanocephala, and T. petrocchiae coincided with the Caatinga of northeastern Brazil (Figure 4). We also noted higher probability of $R$. robustus and $R$. pictipes in northern Brazil (Figure 5), $T$. rubrovaria in the south (Figure 6), and T. tibiamaculata and T. vitticeps in the Atlantic Forest (Figure 7).

3.3. Factors That Determine Species' Distributions. As noted in 3.1 and 3.2, clear associations exist between species' ranges of occurrence and biomes. The overall map diversity among the 16 species modeled (Figure 8) indicates that the areas most favorable for the occurrence of these species are concentrated in the Cerrado and Caatinga, in the diagonal of open areas of eastern South America; other concentrations were in open areas of the Amazon, especially in the state of Roraima.

The view of triatomine species' distributions across Brazilian environmental space shows the broad environmental diversity of the subfamily (Figure 9). Essentially all environmental conditions represented in the country are inhabited by one or more of the 16 species analyzed. Most of the species sort out by the region in which they are distributed: for example, $R$. pictipes and $R$. robustus in the Amazon, Triatoma sordida and R. neglectus in the Cerrado, T. brasiliensis and P. lutzi in the Caatinga, and T. rubrovaria in the far south. In sum, though, the view is of all of Brazil as having some suite of triatomine species present, such that almost nowhere is Chagas transmission risk negligible, although clearly some areas are at much higher risk than others. 


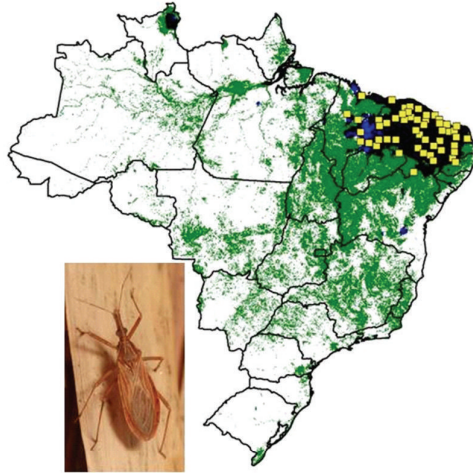

(a)

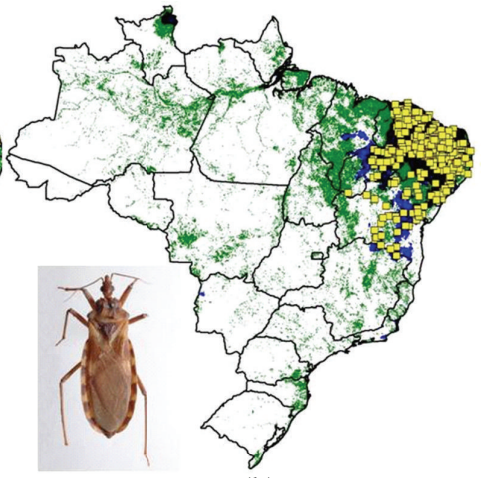

(b)
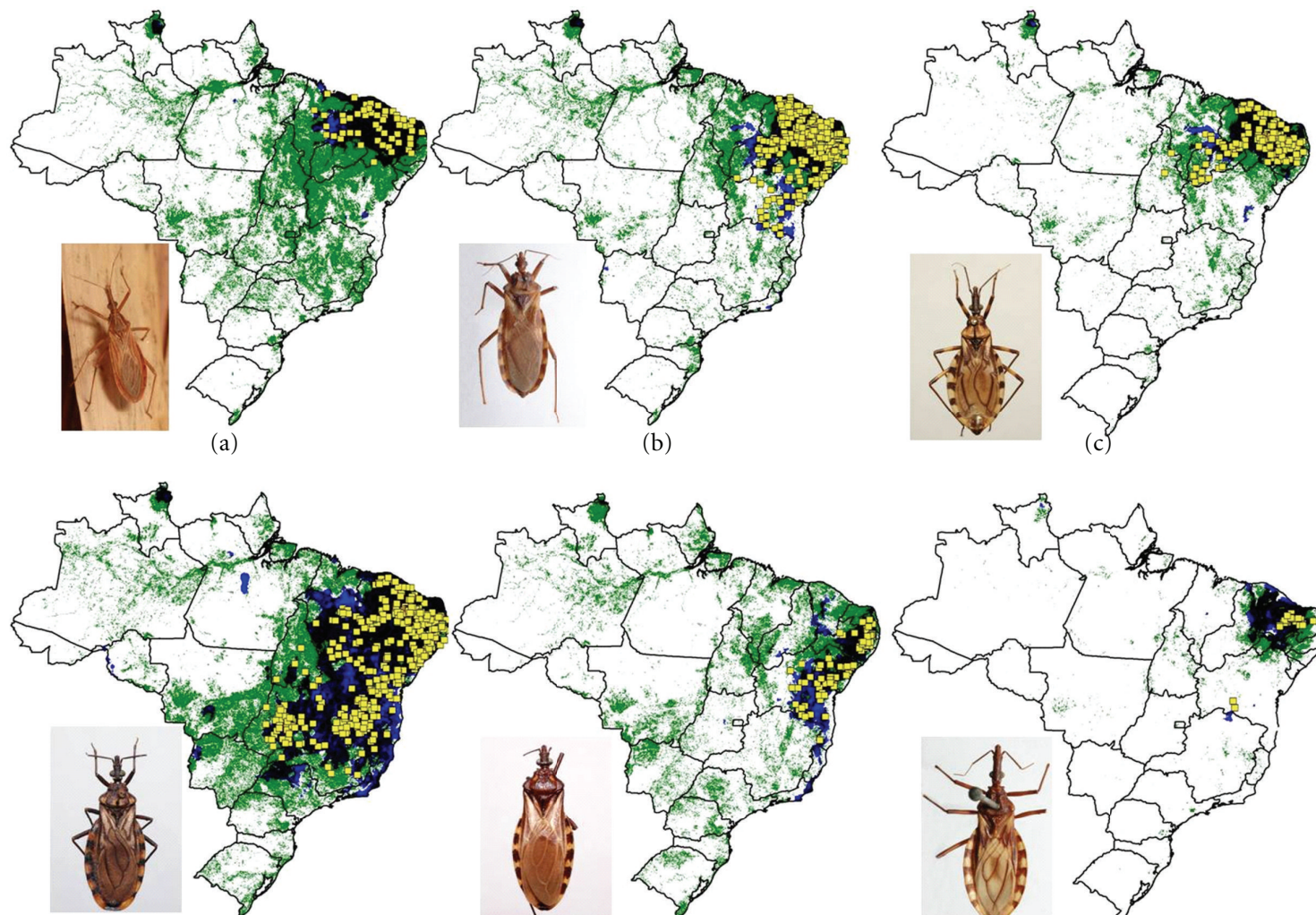

3
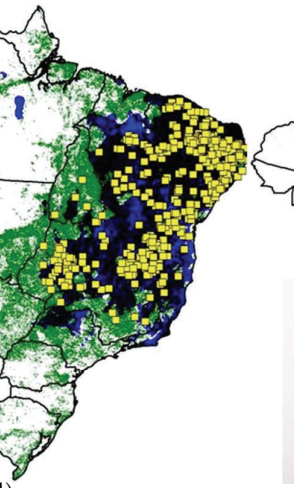

(d)
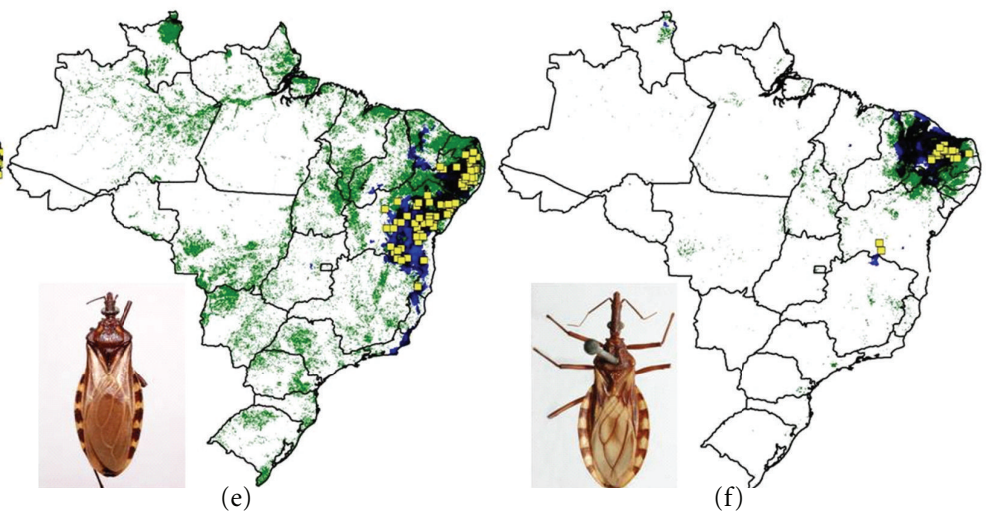

Figure 4: Ecological niche models projected as potential distributions for triatomine species in northeastern Brazil. (a) R. nasutus, (b) P. lutzi, (c) T. brasiliensis, (d) T. pseudomaculata, (e) T. melanocephala, and (f) T. petrocchiae.

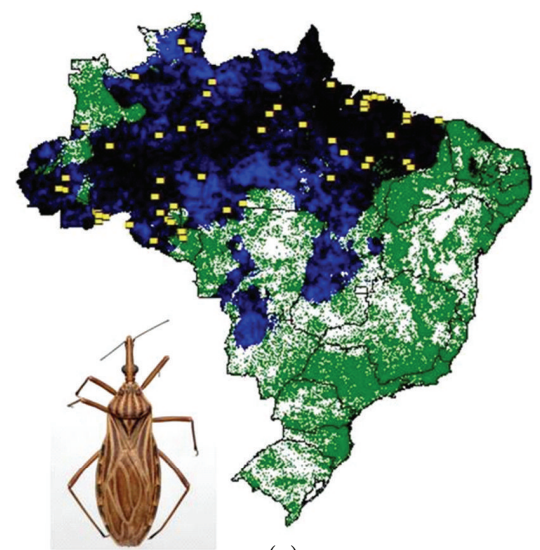

(a)

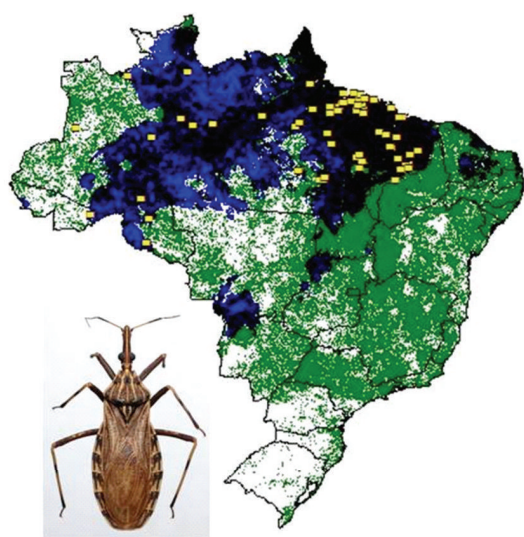

(b)

FIGURE 5: Ecological niche models projected as potential distributions for Amazonian triatomine species. (a) R. robustus, and (b) R. pictipes.

\section{Discussion}

This study analyses the geographic distributions of the 62 species of triatomines in Brazil. We found that the great majority of species has a distribution restricted to fewer than 20 municipalities across Brazil. The analysis of the distribution of 16 synanthropic species broadly distributed in Brazil shows clear associations with Brazilian biomes, indicating the Cerrado and Caatinga as the ones presenting the highest diversity. The Brazilian states presenting the highest numbers of species are Bahia and Mato Grosso. The results suggest that essentially all environmental conditions represented across the country are inhabited by one or more of the 16 species analyzed.

Panstrongylus megistus was the species most broadly distributed throughout Brazil, as pointed out by Silveira [83]. The Atlantic Forest seems to represent the center of the range of $P$. megistus [84], although the species is also broadly distributed in humid areas of the Cerrado ("matas de galeria") and Caatinga (forest remnants). P. megistus shows 


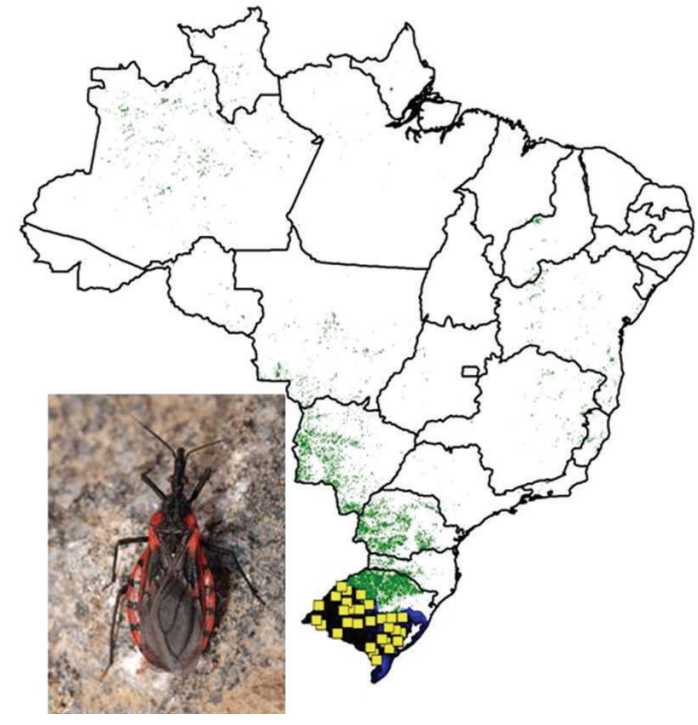

FIGURE 6: Ecological niche models projected as potential distribution for T. rubrovaria.

distinct levels of adaptation to domiciliary environments: in the south, it occurs mainly in sylvatic ecotopes [85] while in the southeast and in the northeast areas, where it is of epidemiologic importance, it occurs mainly in artificial ecotopes [84, 86, 87]. P. megistus seems to prefer hollow trees in arboreal habitats [88, 89] often associated with marsupials (Didelphis spp.), which are frequently infected by T. cruzi; this natural history explains the high levels of natural infection of $P$. megistus when compared to other triatomine vector species [90]. The broad geographic distribution, the acknowledged capacity to invade and colonize domiciles, and the high levels of T. cruzi infection indicate that P. megistus is the species of the greatest epidemiologic importance in Brazil after the control of $T$. infestans.

P. geniculatus is another triatomine species that is very broadly distributed in Brazil and the Americas, occurring in at least 16 countries $[39,48]$. In sylvatic environments $P$. geniculatus preferentially inhabits armadillo nests (Dasypus spp.) $[65,88,89]$ and domiciliary invasion by adults has been detected in several Brazilian states [6]; peridomiciliary colonies have also been found [91]. Nonetheless, its synanthropic behavior and vectorial competency are not as relevant as those of $P$. megistus. The bite of this triatomine is painful and causes allergic reactions in hosts, making blood meals in domestic environments difficult, consequently reducing the chances of colonization of artificial ecotopes [92]. The broad ranges of $P$. geniculatus and P. megistus could be facilitated naturally by mammals (marsupials and armadillos); future studies analyzing the geographic distribution of these triatomines in tandem with their potential hosts could clarify these possibilities.

In the Cerrado, the species most broadly distributed were $T$. sordida and $R$. neglectus. T. sordida occurs naturally under tree bark and also inhabits bird nests [93]. It is the most frequently captured species by entomological surveillance in Brazil $[92,94]$. However, the risk of T. cruzi transmission by $T$. sordida is relatively low due either to the fact that it inhabits mainly the peridomiciliary ecotopes or to its ornithophilic behavior [88, 95]. According to Forattini [84] the areas of higher occurrence of $T$. sordida are the ones related to the agricultural activities in the past, what could explain its presence in areas that suffered ecologic impact due to significant loss of vegetation. It is important to stress that this process has been documented in the last decades in the Cerrado [96].

Rhodnius neglectus is widespread in the Cerrado, and plays an important role in the enzootic transmission of the T. cruzi [97]. Besides the invasion of adults in domiciles [54], the domiciliary colonization of $R$. neglectus has also been recorded in the states of Minas Gerais, São Paulo, and Goiás $[98,99]$. R. neglectus occurs mainly in sylvatic environments, inhabiting different species of palm trees in Brazil [32, 55, 100]. The role of the peridomiciliary palm trees as a source of synanthropic $R$. neglectus must be evaluated in future studies.

Triatoma sordida and $R$. neglectus have also been recorded in other biomes (e.g., Caatinga and Pantanal). One of the possible explanations for this broad distribution would be passive transportation by birds. The dispersal could be facilitated by the fact that the eggs could be attached on the feathers, as suggested for the Rhodniini. Another possibility would be the transport of nymphs among the feathers as already shown for T. sordida [101]. One of the lines of evidence of this kind of dispersal is the coincidence between the distribution of the $R$. neglectus and birds like Phacellodomus ruber and Pseudoseisura cristata [32].

Triatoma costalimai seems to be endemic in the Cerrado. This species has been frequently captured in sylvatic environments (calcareous rocks), and also in peri- and intradomiciliar ecotopes in the municipalities of northeastern Goiás, with high rates of T. cruzi infection [102-104]. The geographic distribution of T. costalimai in the Cerrado remains poorly known, so research is needed to clarify its synanthropic behavior and vectorial capacity. In addition, ecological studies of other triatomine species in the Cerrado should be carried out to improve knowledge of the species occurring in this biome.

Triatoma brasiliensis, T. pseudomaculata, P. lutzi, and $R$. nasutus are broadly distributed in the Caatinga. T. brasiliensis is the most important vector species in northeastern Brazil $[86,105]$. In sylvatic environments, it frequently inhabits rock crops in association with rodents (Kerodon rupestris) presenting significant levels of natural infection by T. cruzi [106]. The occurrence of T. brasiliensis may be associated with the distribution of the rock formations and "chapadas" in the northeast region of Brazil. This species is frequently found infesting houses in five states (MA, PI, CE, RN, and $\mathrm{PB})[17,107,108]$. It can also be found in very low numbers in the border areas of its distribution in the states of Tocantins and Pernambuco. The other four members of the T. brasiliensis species complex are either less synanthropic $(T$. b. macromelasoma and T. juazeirensis) or exclusively sylvatic (T. melanica) $[21,22]$. T. sherlocki, recently included in this species complex, seems to be in the process of adaptation to the domiciliary environment [109].

Triatoma pseudomaculata occurs under bark of trees and in bird nests [88], presenting low percentages of natural 


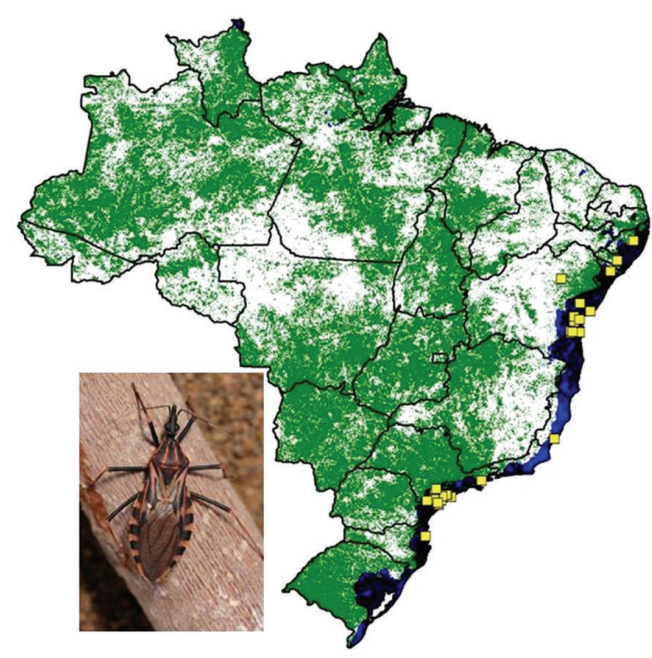

(a)

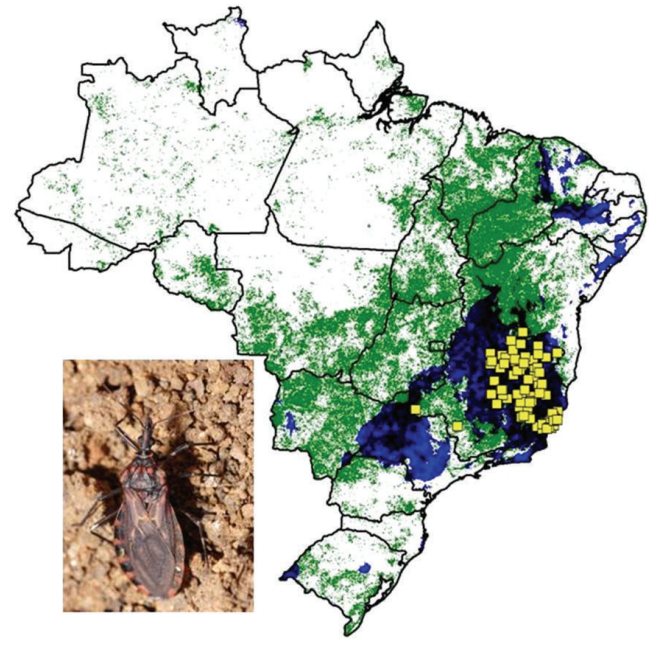

(b)

Figure 7: Ecological niche models projected as potential distributions for Atlantic Forest triatomine species. (a) T. tibiamaculata and (b) T. vitticeps.

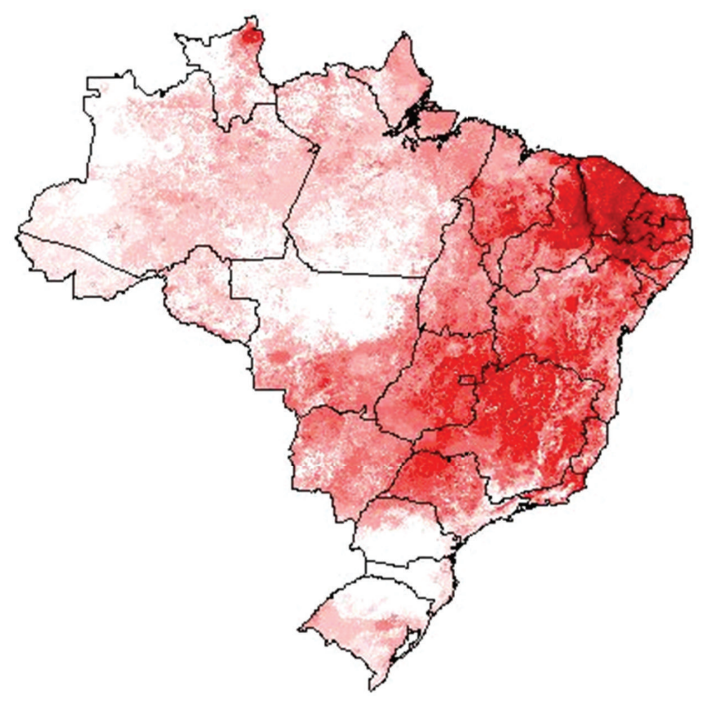

FIgURE 8: Triatomine species diversity map of Brazil, based on ecological niche models for 16 species of triatomine bugs. White areas have no species predicted as occurring, out of the 16 included in this analysis, while the darkest red areas have 13 species predicting as cooccurring.

infection by T. cruzi [86]. Although T. pseudomaculata can be found more frequently in peridomiciliary habitats, feeding generally on birds, in Ceará and Minas Gerais, full domiciliation has been observed $[110,111]$. In some areas of the northeast, T. pseudomaculata has been the most common species after T. brasiliensis, so it must be kept under constant vigilance [86]. The presence of T. pseudomaculata in domiciliary environments has been linked to climate change and deforestation $[111,112]$. One risk factor for domiciliation appears the passive transportation in wood for domestic use and construction of fences [92].

The epidemiologic importance of Panstrongylus lutzi has been increasing in the last years. This species was the fifth most frequently found in captures across 12 Brazilian states in recent years $[13,105]$. P. lutzi occurs in Caatinga and can be found inhabiting armadillo nests [113]; however, it has a much more eclectic diet in domestic environments and shows high levels of natural infection [45].

Rhodnius nasutus is found predominantly in Caatinga in the Northeast inhabiting palm trees of the species Copernicia prunifera $[114,115]$. Nonetheless, $R$. nasutus may also occur in other palms and trees in the Caatinga $[53,116]$. Although $R$. nasutus be considered as endemic to Caatinga, this species was registered in transitional areas with the Amazon forest (e.g., in the Maranhão Babaçu forests) and also with Cerrado [36].

The geographic distribution of Triatoma melanocephala and $T$. petrocchiae was more restricted than the abovementioned species. Triatoma melanocephala appears to occur in more humid areas than T. petrochiae. The natural habitats and food sources of these two species are little known [88], demanding further ecological study to clarify their vectorial potential in transmission of T. cruzi to humans.

Triatoma tibiamaculata and T. vitticeps present a geographic distribution more restricted to the Atlantic Forest. The former is frequently attracted by light but rarely colonizes houses [92]. This species was likely responsible for the contamination of the sugar cane juice that caused several cases of oral transmission recorded in the Santa Catarina [117]. In Bahia, T. tibiamaculata infected by T. cruzi has been found frequently in urban areas, mainly in the warmer months [118]. Adult specimens of $T$. vitticeps have been captured in rural areas of municipalities in Rio de Janeiro, Minas Gerais, and Espírito Santo [47, 62]. In contrast to T. tibiamaculata, T. vitticeps colonizes peridomiciliary areas, increasing risk of transmission of T. cruzi to humans [62, 92].

Rhodnius robustus and $R$. pictipes are broadly distributed in the Amazon region, as pointed out by Abad-Franch and Monteiro [119]. These species have several Amazonian palm trees species as their natural habitats, and present 


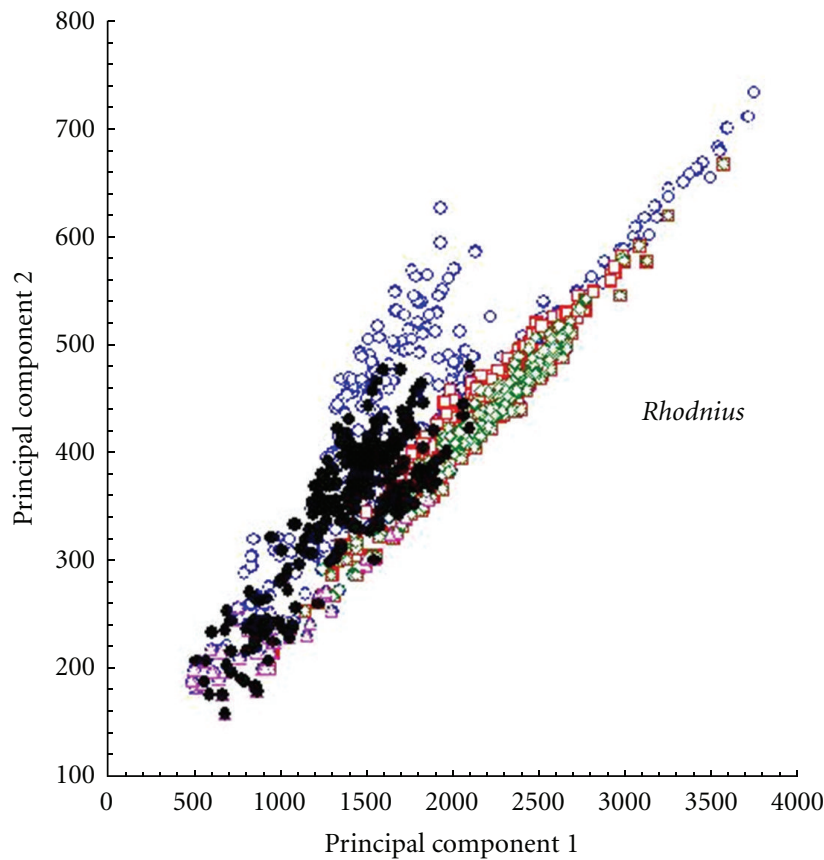

Conditions across Brazil

$\square$ Rhodnius robustus

$\diamond$ Rhodnius pictipes

(a)

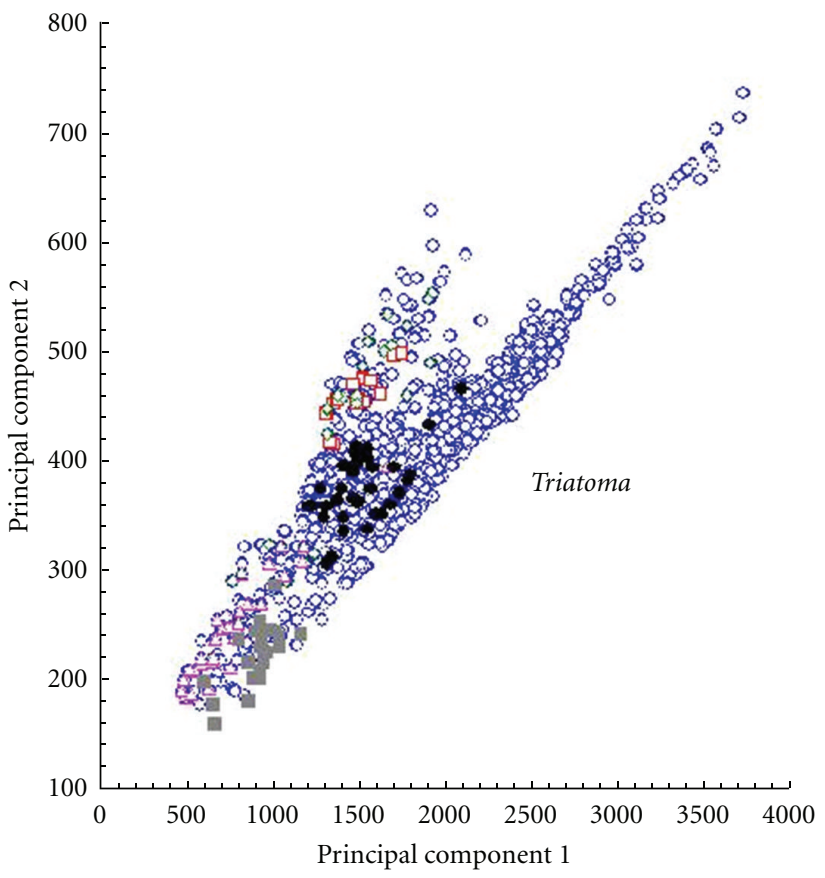

Conditions across Brazi

$\square$ Triatoma rubrovaria

$\diamond$ Triatoma tibiamaculata $\triangle$ Rhodnius nasutus

- Rhodnius neglectus
$\triangle$ Triatoma melanocephala
- Triatoma costalimai
- Triatoma petrocchiae

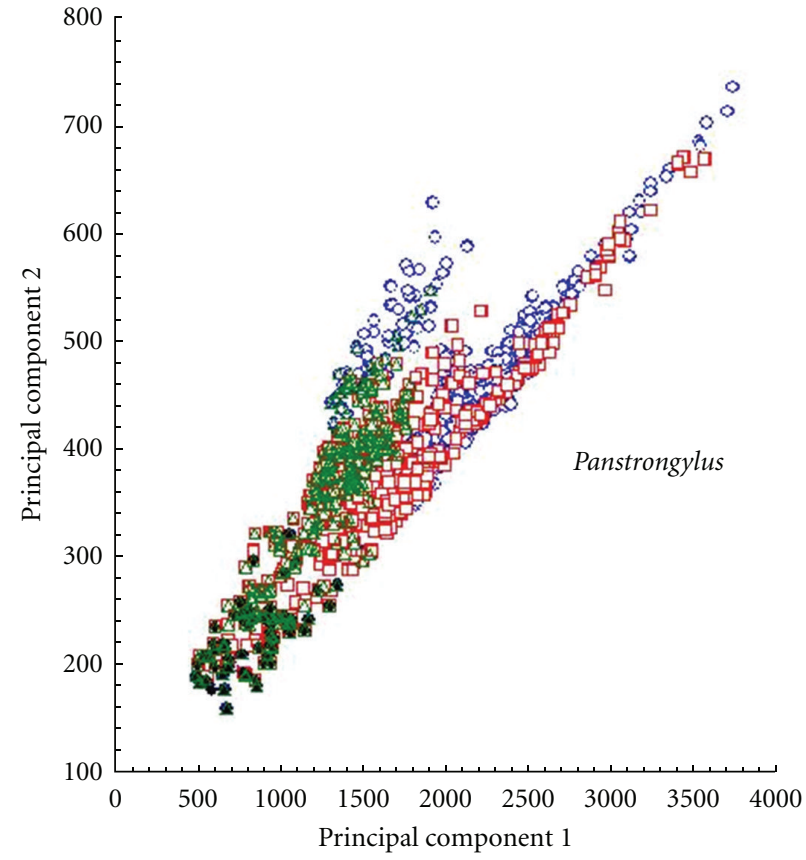

Conditions across Brazil

$\square$ Panstrongylus geniculatus

- Panstrongylus lutzi

$\triangle$ Panstrongylus megistus

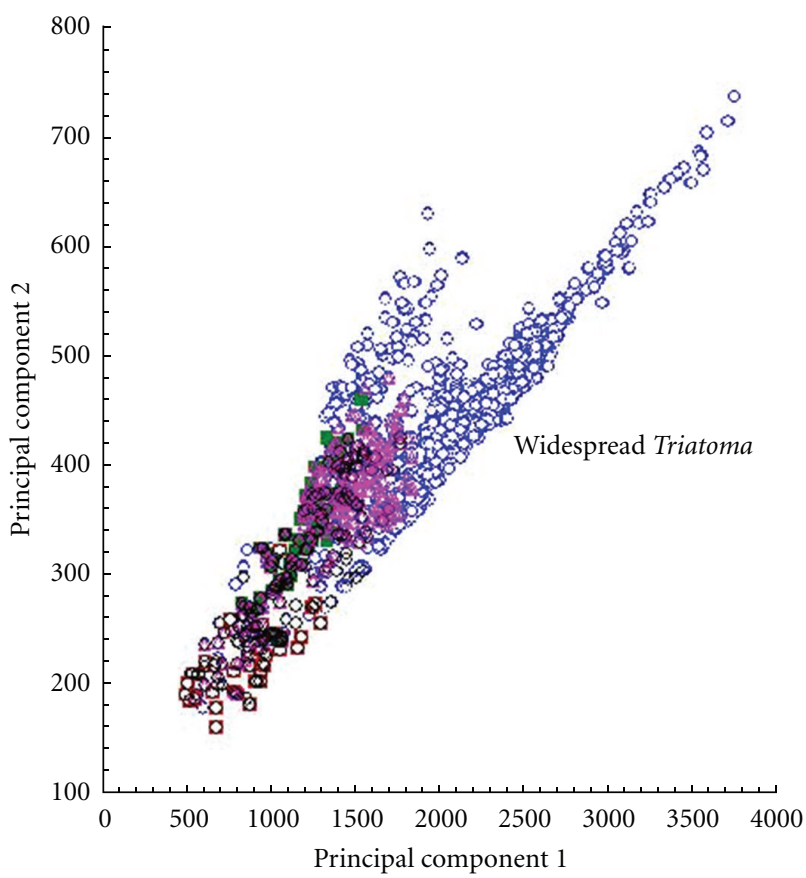
- Conditions across Brazil
$\triangle$ Triatoma sordida
$\square$ Triatoma brasiliensis
- Triatoma pseudomaculata
- Triatoma vitticeps

(d)

FIgURE 9: Distribution of 16 triatomine species in Brazil with respect to environmental variation summarized as the first two principal components summarizing variation in seven climatic dimensions. To provide a view of species' responses to environmental variation across Brazil, we plotted 1000 random points across the country, and assigned to each (1) the predicted presence or absence of each species and (2) the values of the first two principal components extracted from the bioclimatic data set. 
high percentages of natural infection by T. cruzi $[55,120]$. Invasion of houses by adults, apparently related to artificial light sources, should favor transmission of T. cruzi to humans either by direct contact or by food contamination. This last possibility has been recorded frequently in the Amazon, where Chagas disease has been considered emergent [60, 121, 122]. Other possible scenarios of transmission in the Amazon would be of triatomine invasion of peridomiciliary ecotopes, as for P. geniculatus in Pará [91] and T. maculata in Roraima [44].

Triatoma rubrovaria presents a geographic distribution restricted to the Pampas biome in the south. In natural environments, the species can be found under rocks (sometimes very near to domiciles), where it feeds on several animals, including insects [123]. After the control of T. infestans, occurrence of this species has been increasing in Rio Grande do Sul $[13,124]$.

The low occurrence of $T$. infestans detected in the present study is a further evidence for the effective reduction of this species in Brazil by the control programs [13, 125]. However, finding residual populations in Rio Grande do Sul and Bahia emphasizes the importance of constant entomological surveillance to avoid reinvasion by $T$. infestans.

\section{Conclusions}

Our results show that all environmental conditions in Brazil are favorable for one or more of the triatomine species analyzed, such that almost nowhere is Chagas transmission risk negligible. ENM presents a means of viewing species' ecology and biogeography across broad regions. It is by no means a substitute for detailed populational evaluations and natural history observations. Rather, used in tandem with local-scale studies, niche modeling provides complementary information. This study follows long years of previous exploration of these methodologies, and represents a step toward a complete distributional summary of the triatomines of Brazil.

\section{Acknowledgments}

This work was supported by the Conselho Nacional de Desenvolvimento Científico e Tecnológico (CNPq) and Coordenação de Aperfeiçoamento de Pessoal de Nível Superior (CAPES). The authors are also grateful to all health agents of Brazilian states who provided information on the distribution of triatomines.

\section{References}

[1] C. Chagas, "Nova tripanozomiase humana. Estudos sôbre a morfologia e o ciclo evolutivo de Schizotrypanum cruzi n. gen., n. sp. ajente etiolójico de nova entidade morbida do homem," Memorias do Instituto Oswaldo Cruz, vol. 1, no. 1, pp. 159-218, 1909.

[2] J. C. P. Dias, A. C. Silveira, and C. J. Schofield, "The impact of Chagas disease control in Latin America-a review," Memorias do Instituto Oswaldo Cruz, vol. 97, no. 5, pp. 603612, 2002.
[3] M. A. Miles, "The discovery of Chagas disease: progress and prejudice," Infectious Disease Clinics of North America, vol. 18, no. 2 , pp. 247-260, 2004.

[4] J. R. Coura and P. A. Viñas, "Chagas disease: a new worldwide challenge," Nature, vol. 465, no. 7301, pp. S6-S7, 2010.

[5] G. A. Schmunis and Z. E. Yadon, "Chagas disease: a Latin American health problem becoming a world health problem," Acta Tropica, vol. 115, no. 1-2, pp. 14-21, 2010.

[6] A. C. Silveira, V. R. Feitosa, and R. Borges, "Distribution of triatominae captured in a domestic environment, 1975/83, Brazil," Revista Brasileira de Malariologia e Doenças Tropicais, vol. 36, pp. 15-312, 1984.

[7] M. E. Camargo, G. R. da Silva, E. A. de Castilho, and A. C. Silveira, "Serological survey of the prevalence of Chagas' infection in Brazil, 1975/1980," Revista do Instituto de Medicina Tropical de Sao Paulo, vol. 26, no. 4, pp. 192-204, 1984.

[8] World Health Organization, "Control of Chagas disease," Tech. Rep. series 905, WHO, Geneva, Switzerland, Second report of the WHO Expert Committee, 2002.

[9] F. Guhl, "Chagas disease in Andean countries," Memorias do Instituto Oswaldo Cruz, vol. 102, no. 1, pp. 29-37, 2007.

[10] A. Rassi Jr., A. Rassi, and J. A. Marin-Neto, "Chagas disease," The Lancet, vol. 375, no. 9723, pp. 1388-1402, 2010.

[11] A. A. Moncayo and A. C. Silveira, "Current epidemiological trends for Chagas disease in Latin America and future challenges in epidemiology, surveillance and health policy," Memorias do Instituto Oswaldo Cruz, vol. 104, no. 1, pp. 1730, 2009.

[12] C. J. Schofield, J. Jannin, and R. Salvatella, "The future of Chagas disease control," Trends in Parasitology, vol. 22, no. 12, pp. 583-588, 2006.

[13] A. C. Silveira and J. C. P. Dias, "O controle da transmissão vetorial," Revista da Sociedade Brasileira de Medicina Tropical, vol. 44, pp. 52-63, 2011.

[14] A. L. Ostermayer, A. D.C. Passos, A. C. Silveira, A. W. Ferreira, V. Macedo, and A. R. Prata, "O inquérito nacional de soroprevalência de avaliação do controle da doença de chagas no Brasil (2001-2008)," Revista da Sociedade Brasileira de Medicina Tropical, vol. 44, pp. 108-121, 2011.

[15] Ministério da Saúde, Secretaria de Vigilância em Saúde, Departamento de Vigilância Epidemiológica, Guia de vigilância epidemiológica, Ministério da Saúde, Secretaria de Vigilância em Saúde, Departamento de Vigilância Epidemiológica, Brasília, Brazil, 7 edition, 2009.

[16] F. Guhl, N. Pinto, and G. Aguilera, "Sylvatic Triatominae: a new challenge in vector control transmission," Memorias do Instituto Oswaldo Cruz, vol. 104, no. 1, pp. 71-75, 2009.

[17] J. Costa and M. Lorenzo, "Biology, diversity and strategies for the monitoring and control of triatomines-Chagas disease vectors," Memorias do Instituto Oswaldo Cruz, vol. 104, no. 1, pp. 46-51, 2009.

[18] A. C. Silveira, "Os novos desafios e perspectivas futuras do controle," Revista da Sociedade Brasileira de Medicina Tropical, vol. 44, supplement 2, pp. 122-124, 2011.

[19] C. Galvão, R. Carcavallo, D. S. Rocha, and J. Jurberg, "A checklist of the current valid species of the subfamily Triatominae Jeannel, 1919 (Hemiptera, Reduviidae) and their geographical distribution, with nomenclatural and taxonomic notes," Zootaxa, vol. 202, pp. 1-36, 2003.

[20] D. Forero, C. Weirauch, and M. Baena, "Synonymy of the reduviid (Hemiptera: Heteroptera) genus Torrealbaia (Triatominae) with Amphibolus (Harpactorinae), with notes 
on Amphibolus venator (Klug, 1830)," Zootaxa, vol. 670, pp. 1-12, 2004.

[21] J. Costa, A. M. Argolo, and M. Felix, "Redescription of Triatoma melanica Neiva \& Lent, 1941, new status (Hemiptera: Reduviidae: Triatominae)," Zootaxa, no. 1385, pp. 47-52, 2006.

[22] J. Costa and M. Felix, "Triatoma juazeirensis sp. nov. from the state of Bahia, northeastern Brazil (Hemiptera: Reduviidae: Triatominae)," Memorias do Instituto Oswaldo Cruz, vol. 102, no. 1, pp. 87-90, 2007.

[23] C. J. Schofield and C. Galvão, "Classification, evolution, and species groups within the Triatominae," Acta Tropica, vol. 110, no. 2-3, pp. 88-100, 2009.

[24] D. Frías-Lasserre, "A new species and karyotype variation in the bordering distribution of Mepraia spinolai (Porter) and Mepraia gajardoi Frías et al (Hemiptera: Reduviidae: Triatominae) in Chile and its parapatric model of speciation," Neotropical Entomology, vol. 39, no. 4, pp. 572-583, 2010.

[25] A. T. Peterson, "Ecologic niche modeling and spatial patterns of disease transmission," Emerging Infectious Diseases, vol. 12, no. 12, pp. 1822-1826, 2006.

[26] A. T. Peterson, J. Soberón, R. G. Pearson et al., Ecological Niches and Geographic Distributions, Princeton University Press, Princeton, NJ, USA, 2011.

[27] J. Costa, A. T. Peterson, and C. B. Beard, "Ecologic niche modeling and differentiation of populations of Triatoma brasiliensis neiva, 1911, the most important Chagas' disease vector in northeastern Brazil (Hemiptera, Reduviidae, Triatominae)," American Journal of Tropical Medicine and Hygiene, vol. 67, no. 5, pp. 516-520, 2002.

[28] A. Townsend Peterson, V. Sánchez-Cordero, C. Ben Beard, and J. M. Ramsey, "Ecologic niche modeling and potential reservoirs for Chagas disease, Mexico," Emerging Infectious Diseases, vol. 8, no. 7, pp. 662-667, 2002.

[29] C. B. Beard, G. Pye, F. J. Steurer et al., "Chagas disease in a domestic transmission cycle in southern Texas, USA," Emerging Infectious Diseases, vol. 9, no. 1, pp. 103-105, 2003.

[30] J. López-Cárdenas, F. E. Gonzalez Bravo, P. M. Salazar Schettino et al., "Fine-scale predictions of distributions of Chagas disease vectors in the state of Guanajuato, Mexico," Journal of Medical Entomology, vol. 42, no. 6, pp. 1068-1081, 2005.

[31] C. A. Sandoval-Ruiz, J. L. Zumaquero-Rios, and O. R. RojasSoto, "Predicting geographic and ecological distributions of triatomine species in the southern Mexican state of Puebla using ecological niche modeling," Journal of Medical Entomology, vol. 45, no. 3, pp. 540-546, 2008.

[32] R. Gurgel-Gonçalves and C. A. C. Cuba, "Predicting the potential geographical distribution of Rhodnius neglectus (Hemiptera, Reduviidae) based on ecological niche modeling," Journal of Medical Entomology, vol. 46, no. 4, pp. 952960, 2009.

[33] R. Gurgel-Gonçalves and R. B. Silva, "Analysis of the geographical distribution of Psammolestes Bergroth (Hemiptera: Heteroptera: Reduviidae: Triatominae) in South America, with new records of Psammolestes tertius Lent \& Jurberg," Zootaxa, no. 2033, pp. 41-48, 2009.

[34] S. Arboleda, D. E. Gorla, X. Porcasi, A. Saldaña, J. Calzada, and N. Jaramillo-O, "Development of a geographical distribution model of Rhodnius pallescens Barber, 1932 using environmental data recorded by remote sensing," Infection, Genetics and Evolution, vol. 9, no. 4, pp. 441-448, 2009.
[35] C. N. Ibarra-Cerdeña, V. Sánchez-Cordero, A. T. Peterson, and J. M. Ramsey, "Ecology of North American Triatominae," Acta Tropica, vol. 110, no. 2-3, pp. 178-186, 2009.

[36] T. A. Batista and R. Gurgel-Gonçalves, "Ecological niche modelling and differentiation between Rhodnius neglectus lent, 1954 and Rhodnius nasutus Stål, 1859 (Hemiptera: Reduviidae: Triatominae) in Brazil," Memorias do Instituto Oswaldo Cruz, vol. 104, no. 8, pp. 1165-1170, 2009.

[37] R. Gurgel-Gonçalves, J. B.C. Ferreira, A. F. Rosa, M. E. Bar, and C. Galvão, "Geometric morphometrics and ecological niche modelling for delimitation of near-sibling triatomine species," Medical and Veterinary Entomology, vol. 25, no. 1, pp. 84-93, 2011.

[38] H. Lent and P. Wygodzisnky, "Revision of the Triatominae (Hemiptera, Reduviidae) and their significance as vectors of Chagas' disease," Bulletin of the American Museum of Natural History, vol. 163, no. 3, pp. 123-520, 1979.

[39] R. U. Carcavallo, S. I. Curto de Casas, I. Sherlock et al., "Geographical distribution and alti-latitudinal dispersion," in Atlas of Chagas Disease Vectors in the Americas, R. U. Carcavallo, I. Galíndez Girón, J. Jurberg, and H. Lent, Eds., vol. 2, pp. 747-792, 1999.

[40] J. Alencar, R. U. Carcavallo, J. Jurberg, and H. Gil-Santana, "Occurrence of Microtriatoma borbai Lent \& Wygodzinsky, 1979, in Rio de Janeiro State, Brazil, (Hemiptera, Reduvidae, Triatominae)," Entomología y Vectores, vol. 7, no. 4, pp. 445447, 2000.

[41] C. E. Almeida, M. C. Vinhaes, J. R. De Almeida, A. C. Silveira, and J. Costa, "Monitoring the domiciliary and peridomiciliary invasion process of Triatoma rubrovaria in the state of Rio Grande do Sul, Brazil," Memorias do Instituto Oswaldo Cruz, vol. 95, no. 6, pp. 761-768, 2000.

[42] C. Galvão, D. S. Rocha, J. Jurberg, and R. U. Carcavallo, "New geographical distribution of Triatoma deaneorum Galvão, Souza \& Lima 1967, new designation for Triatoma deanei (Hemiptera, Reduviidae)," Revista da Sociedade Brasileira de Medicina Tropical, vol. 34, no. 6, pp. 587-589, 2001.

[43] S. P. Carneiro Freitas, A. L. Carneiro Freitas, and T. C. Monte Gonçalves, "Occurrence of Panstrongylus lutzi, in peridomiciliary areas, State of Ceará, Brazil," Revista de Saude Publica, vol. 38, no. 4, pp. 579-580, 2004.

[44] J. F. Luitgards-Moura, J. Borges-Pereira, J. Costa, P. L. Zauza, and M. G. Rosa-Freitas, "On the possibility of autochthonous chagas disease in Roraima, Amazon Region, Brazil, 20002001," Revista do Instituto de Medicina Tropical de Sao Paulo, vol. 47, no. 1, pp. 45-54, 2005.

[45] L. Caranha, E. S. Lorosa, D. D. S. Rocha, J. Jurberg, and C. Galvão, "Feeding sources evaluation of Panstrongylus lutzi (Neiva \& Pinto, 1923) (Hemiptera: Reduviidae: Triatominae) in the state of Ceará," Revista da Sociedade Brasileira de Medicina Tropical, vol. 39, no. 4, pp. 347-351, 2006.

[46] L. P. Alves Martins, R. E. Pires Castanho, C. Casanova et al., "Rupestrian triatomines infected by Trypanosomatidae, collected in Quaraí, Rio Grande do Sul, 2003," Revista da Sociedade Brasileira de Medicina Tropical, vol. 39, no. 2, pp. 198-202, 2006.

[47] C. B. Dos Santos, G. R. Leite, G. E. Melim Ferreira, and A. L. Ferreira, "Natural infection of Triatoma vitticeps (Stal, 1859) with flagellates morphologically similar to Trypanosoma cruzi (Chagas, 1909) in Espírito Santo State," Revista da Sociedade Brasileira de Medicina Tropical, vol. 39, no. 1, pp. 89-91, 2006. 
[48] G. R. Leite, C. B. Santos, and A. Falqueto, "Insecta, Hemiptera, Reduviidae, Panstrongylus geniculatus: geographic distribution map," Check List, vol. 3, no. 2, pp. 147152, 2007.

[49] M. A. De Oliveira, R. D. C. M. De Souza, and L. Diotaiuti, "Redescription of the genus Cavernicola and the tribe Cavernicolini (Hemiptera: Reduviidae: Triatominae), with morphological and morphometric parameters," Zootaxa, no. 1457, pp. 57-68, 2007.

[50] M. G. Pavan and F. A. Monteiro, "A multiplex PCR assay that separates Rhodnius prolixus from members of the Rhodnius robustus cryptic species complex (Hemiptera: Reduviidae)," Tropical Medicine and International Health, vol. 12, no. 6, pp. 751-758, 2007.

[51] P. S. Almeida, H. R. Santos, J. M. S. Barata, M. T. Obara, and W. Ceretti Jr., "Occurrence of Panstrongylus guentheri Berg (Hemiptera: Reduviidae) in Mato Grosso do Sul State, Brazil," Neotropical Entomology, vol. 37, no. 1, pp. 107-108, 2008.

[52] P. S. Almeida, W. Ceretti, M. T. Obara, H. R. Santos, J. M. S. Barata, and O. Faccenda, "Survey of Triatominae (Hemiptera: Reduviidae) fauna in domestic environments and natural infection by Trypanosomatidae in the state of Mato Grosso do Sul," Revista da Sociedade Brasileira de Medicina Tropical, vol. 41, no. 4, pp. 374-380, 2008.

[53] F. B. S. Dias, C. M. Bezerra, E. M. De Menezes Machado, C. Casanova, and L. Diotaiuti, "Ecological aspects of Rhodnius nasutus Stål,. 1859 (Hemiptera: Reduviidae: Triatominae) in palms of the Chapada do Araripe in Ceará, Brazil," Memorias do Instituto Oswaldo Cruz, vol. 103, no. 8, pp. 824-830, 2008.

[54] R. Gurgel-Gonçalves, F. Abad-Franch, J. B. C. Ferreira, D. B. Santana, and C. A. C. Cuba, "Is Rhodnius prolixus (Triatominae) invading houses in central Brazil?" Acta Tropica, vol. 107, no. 2, pp. 90-98, 2008.

[55] F. Abad-Franch, F. A. Monteiro, N. Jaramillo, R. GurgelGonçalves, F. B. S. Dias, and L. Diotaiuti, "Ecology, evolution, and the long-term surveillance of vector-borne Chagas disease: a multi-scale appraisal of the tribe Rhodniini (Triatominae)," Acta Tropica, vol. 110, no. 2-3, pp. 159-177, 2009.

[56] C. E. Almeida, P. L. Marcet, M. Gumiel et al., "Phylogenetic and phenotypic relationships among Triatoma carcavalloi (Hemiptera: Reduviidae: Triatominae) and related species collected in domiciles in Rio Grande do sul state, Brazil," Journal of Vector Ecology, vol. 34, no. 2, pp. 164-173, 2009.

[57] C. Bedin, F. Mello, T. S. Wilhelms et al., "Vigilância ambiental: doença de Chagas no Rio Grande do Sul," Boletim Epidemiológico, vol. 11, no. 3, pp. 1-8, 2009.

[58] A. L. Carbajal de la Fuente, X. Porcasi, F. Noireau, L. Diotaiuti, and D. E. Gorla, "The association between the geographic distribution of Triatoma pseudomaculata and Triatoma wygodzinskyi (Hemiptera: Reduviidae) with environmental variables recorded by remote sensors," Infection, Genetics and Evolution, vol. 9, no. 1, pp. 54-61, 2009.

[59] N. F. Fé, L. K. Magalhães, F. A. Fé, S. K. Arakian, W. M. Monteiro, and M. D. G. V. Barbosa, "Occurrences of triatomines in wild and domestic environments in the municipality of Manaus, state of Amazonas," Revista da Sociedade Brasileira de Medicina Tropical, vol. 42, no. 6, pp. 642-646, 2009.

[60] M. C. M. Castro, T. V. Barrett, W. S. Santos, F. AbadFranch, and J. A. Rafael, "Attraction of Chagas disease vectors
(Triatominae) to artificial light sources in the canopy of primary Amazon rainforest," Memorias do Instituto Oswaldo Cruz, vol. 105, no. 8, pp. 1061-1064, 2010.

[61] F. B. S. Dias, M. Quartier, C. A. Romaña, L. Diotaiuti, and M. Harry, "Tamandua tetradactyla Linnaeus, 1758 (Myrmecophagidae) and Rhodnius robustus Larrousse, 1927 (Triatominae) infection focus by Trypanosoma rangeli Tejera, 1920 (Trypanosomatidae) in Attalea phalerata Mart. ex Spreng (Arecaceae) palm tree in the Brazilian Amazon," Infection, Genetics and Evolution, vol. 10, no. 8, pp. 12781281, 2010.

[62] R. D. C. M. de Souza, L. Diotaiuti, M. G. Lorenzo, and D. E. Gorla, "Analysis of the geographical distribution of Triatoma vitticeps (Stål, 1859) based on data of species occurrence in Minas Gerais, Brazil," Infection, Genetics and Evolution, vol. 10, no. 6, pp. 720-726, 2010.

[63] R. Gurgel-Gonçalves and C. A.C. Cuba, "Infestation of thornbird nests (Passeriformes: Furnariidae) by Psammolestes tertius (Hemiptera: Reduviidae) across Brazilian Cerrado and Caatinga ecoregions," Zoologia, vol. 28, no. 3, pp. 411-414, 2011.

[64] D. U. O. Meneguetti, O. Trevisan, R. M. Rosa, and L. M. A. Camargo, "First report of Eratyrus mucronatus, Stal, 1859, (Hemiptera, Reduviidae, Triatominae) in the state of Rondônia, Brazil," Revista da Sociedade Brasileira de Medicina Tropical, vol. 44, no. 4, pp. 511-512, 2011.

[65] M. B. A. Silva, A. V. M. S. Barreto, H. A. da Silva et al., "Synanthropic triatomines (Hemiptera, Reduviidae) in theState of Pernambuco, Brazil: geographical distribution and natural Trypanosoma infection rates between 2006 and 2007," Revista da Sociedade Brasileira de Medicina Tropical. In press.

[66] R. U. Carcavallo and J. Jurberg, “Triatoma baratai sp. n. do estado do Mato Grosso do Sul, Brasil (Hemiptera, Reduviidae, Triatominae)," Entomologia y Vectores, vol. 7, no. 4, pp. 373-387, 2000.

[67] R. U. Carcavallo, J. Jurberg, H. Lent, C. Galvão, M. Steindel, and C. J. Carvalho Pinto, "A new species of the oliveirai complex (new designation for matogrossensis complex) from the state of Rio Grande do Sul, Brazil," Memorias do Instituto Oswaldo Cruz, vol. 96, no. 1, pp. 71-79, 2001.

[68] R. U. Carcavallo, J. Jurberg, D. Da Silva Rocha, C. Galvão, F. Noireau, and H. Lent, "Triatoma vandae sp.n. of the oliveirai complex from the state of Mato Grosso, Brazil (Hemiptera: Reduviidae: Triatominae)," Memorias do Instituto Oswaldo Cruz, vol. 97, no. 5, pp. 649-654, 2002.

[69] V. C. Valente, S. A. S. Valente, R. U. Carcavallo, D. S. Rocha, C. Galvão, and J. Jurberg, "Considerações sobre uma nova espécie do gênero Rhodnius Stal, do Estado do Pará, Brasil (Hemiptera, Reduviidae, Triatominae)," Entomologia y Vectores, vol. 8, no. 1, pp. 65-80, 2001.

[70] A. R. Papa, J. Jurberg, R. U. Carcavallo, R. L. Cerqueira, and J. M. S. Barata, "Triatoma sherlocki sp. n. coletada na Bahia, Brasil (Hemiptera, Reduviidae, Triatominae)," Entomologya y Vectores, vol. 9, pp. 133-146, 2002.

[71] J. Jurberg, D. S. Rocha, and C. Galvão, "Rhodnius zeledoni sp. nov. afim de Rhodnius paraensis Sherlock, Guitton \& Miles, 1977 (Hemiptera, Reduviidae, Triatominae)," Biota Neotropica, vol. 9, no. 1, pp. 123-128, 2009.

[72] D. R. B. Stockwell and A. T. Peterson, "Effects of sample size on accuracy of species distribution models," Ecological Modelling, vol. 148, no. 1, pp. 1-13, 2002. 
[73] M. S. Wisz, R. J. Hijmans, J. Li et al., "Effects of sample size on the performance of species distribution models," Diversity and Distributions, vol. 14, no. 5, pp. 763-773, 2008.

[74] N. Barve, V. Barve, A. Jiménez-Valverde et al., "The crucial role of the accessible area in ecological niche modeling and species distribution modeling," Ecological Modelling, vol. 222, no. 11, pp. 1810-1819, 2011.

[75] J. Soberón and A. T. Peterson, "Interpretation of models of fundamental ecological niches and species' distributional areas," Biodiversity Informatics, vol. 2, pp. 1-10, 2005.

[76] S. Bodbyl-Roels, A. T. Peterson, and X. Xiao, "Comparative analysis of remotely-sensed data products via ecological niche modeling of avian influenza case occurrences in Middle Eastern poultry," International Journal of Health Geographics, vol. 10, no. 21, pp. 1-12, 2011.

[77] R. J. Hijmans, S. E. Cameron, J. L. Parra, P. G. Jones, and A. Jarvis, "Very high resolution interpolated climate surfaces for global land areas," International Journal of Climatology, vol. 25, no. 15, pp. 1965-1978, 2005.

[78] A. T. Peterson and Y. Nakazawa, "Environmental data sets matter in ecological niche modelling: an example with Solenopsis invicta and Solenopsis richteri," Global Ecology and Biogeography, vol. 17, no. 1, pp. 135-144, 2008.

[79] A. Townsend Peterson, M. Papeş, and M. Eaton, “Transferability and model evaluation in ecological niche modeling: a comparison of GARP and Maxent," Ecography, vol. 30, no. 4, pp. 550-560, 2007.

[80] J. Elith, C. H. Graham, R. P. Anderson et al., "Novel methods improve prediction of species' distributions from occurrence data," Ecography, vol. 29, no. 2, pp. 129-151, 2006.

[81] A. T. Peterson, M. Papeş, and J. Soberón, "Rethinking receiver operating characteristic analysis applications in ecological niche modeling," Ecological Modelling, vol. 213, no. 1, pp. 6372, 2008.

[82] R. G. Pearson, C. J. Raxworthy, M. Nakamura, and A. Townsend Peterson, "Predicting species distributions from small numbers of occurrence records: a test case using cryptic geckos in Madagascar," Journal of Biogeography, vol. 34, no. 1, pp. 102-117, 2007.

[83] A. C. Silveira, "O inquérito triatomínico (1975-1983)," Revista da Sociedade Brasileira de Medicina Tropical, vol. 44, supplement 2, pp. 26-32, 2011.

[84] O. P. Forattini, "Biogeography, origin and distribution of Triatominae domicile dispersal in Brazil," Revista de Saude Publica, vol. 14, no. 3, pp. 265-299, 1980.

[85] C. J. R. Ramos, K. C. S. Tavares, L. K. O. Komati, and L. C. Miletti, "Colonization by Panstrongylus megistus (Hemiptera, Reduviidae, Triatominae) inside homes in São José do Cerrito, SC: first report," Revista da Sociedade Brasileira de Medicina Tropical, vol. 41, no. 4, pp. 421-423, 2008.

[86] J. C. Dias, E. M. Machado, A. L. Fernandes, and M. C. Vinhaes, "General situation and perspectives of Chagas disease in Northeastern Region, Brazil," Cadernos de Saude Publica, vol. 16, pp. S13-S34, 2000.

[87] M. M. Villela, J. M. B. Souza, V. P. Melo, and J. C. P. Dias, "Evaluation of the Chagas disease control program and presence of Panstrongylus megistus in centralwestern Minas Gerais state, Brazil," Cadernos de Saude Publica, vol. 25, no. 4, pp. 907-917, 2009.

[88] R. U. Carcavallo, M. E. F. Rodríguez, R. Salvatella et al., "Habitats and related fauna," in Atlas of Chagas Disease Vectors in the Americas, R. U. Carcavallo, I. Galíndez Girón, J. Jurberg, and H. Lent, Eds., vol. 2, pp. 561-600, Editora Fiocruz, Rio de Janeiro, Brazil, 1988.
[89] J. S. Patterson, S. E. Barbosa, and M. D. Feliciangeli, "On the genus Panstrongylus Berg 1879: evolution, ecology and epidemiological significance," Acta Tropica, vol. 110, no. 2-3, pp. 187-199, 2009.

[90] O. P. Forattini, O. A. Ferreira, E. O. da Rochae Silva, and E. X. Rabello, "Ecological aspects of American Trypanosomiasis. VIII. The domicile of Panstrongylus megistus and its extradomiciliary presence," Revista de Saude Publica, vol. 11, no. 1, pp. 73-86, 1977.

[91] V. C. Valente, "Potential for domestication of Panstrongylus geniculatus (Latreille, 1811) (Hemiptera: Reduviidae: Triatominae) in the municipality of Muaná, Marajó Island, Pará state, Brazil," Revista da Sociedade Brasileira de Medicina Tropical, vol. 32, no. 5, pp. 595-597, 1999.

[92] L. Diotaiuti, "Triatomines vectors os Trypanosoma cruzi infections," in Emerging Chagas Disease, A. Teixeira, M. Vinaud, and A. Maria Castro, Eds., pp. 24-39, Bentham Science Publishers, 2009.

[93] L. Diotaiuti, C. F. Loiola, P. L. Falcão, and J. C. Dias, “The ecology of Triatoma sordida in natural environments in two different regions of the state of Minas Gerais, Brazil," Revista do Instituto de Medicina Tropical de Sao Paulo, vol. 35, no. 3, pp. 37-45, 1993.

[94] L. Diotaiuti, B. V. Melo Azeredo, S. C. Uber Busek, and A. J. Fernandes, "Control of Triatoma sordida in the rural peridomestic environment of Porteirinha municipality, Minas Gerais, Brazil," Pan American Journal of Public Health, vol. 3, no. 1, pp. 21-25, 1998.

[95] O. P. Forattini, O. A. Ferreira, E. O. da Rocha e Silva, and E. X. Rabello, "Ecological aspects of South American trypanosomiasis. XV. Development, variation and permanence of Triatoma sordida, Panstrongylus megistus and Rhodnius neglectus in artificial ecotopes," Revista de Saude Publica, vol. 13, no. 3, pp. 220-234, 1979.

[96] C. A. Klink and R. B. Machado, "Conservation of the Brazilian Cerrado," Conservation Biology, vol. 19, no. 3, pp. 707-713, 2005.

[97] R. Gurgel-Gonçalves, E. D. Ramalho, M. A. Duarte et al., "Enzootic transmission of Trypanosoma cruzi and T. rangeli in the Federal District of Brazil," Revista do Instituto de Medicina Tropical de Sao Paulo, vol. 46, no. 6, pp. 323-330, 2004.

[98] M. P. Barretto, A. F. de Siqueira, F. Ferriolli Filho, and J. R. Carvalheiro, "Estudos sôbre reservatórios e vectores silvestres do Trypanosoma cruzi. 23. Observações sôbre criadouros do Rhodnius neglectus Lent, 1954 em biótopos artificiais (Hemiptera, Reduviidae)," Revista do Instituto de Medicina Tropical de Sao Paulo, vol. 10, no. 3, pp. 163-170, 1968.

[99] R. A. Silva, P. R. Bonifácio, and D. M. Wanderley, "Chagas' disease in São Paulo State: a comparative study between systematic search and inhabitants' report of bugs in the area under entomological surveillance," Revista da Sociedade Brasileira de Medicina Tropical, vol. 32, no. 6, pp. 653-659, 1999.

[100] L. Diotaiuti and J. C. Dias, "Occurrence and biology of Rhodnius neglectus Lent, 1954 in palm trees of suburban areas of Belo Horizonte, Minas Gerais," Memorias do Instituto Oswaldo Cruz, vol. 79, no. 3, pp. 293-301, 1984.

[101] O. P. Forattini, E. O. Rocha e Silva, O. A. Ferreira, E. X. Rabello, and D. G. Pattoli, "Ecological aspects of trypanosomiasis. 3. Local dispersion of Triatominae with special reference to Triatoma sordida," Revista de Saude Publica, vol. 5, no. 2, pp. 193-205, 1971. 
[102] D. A. Mello and M. M. Borges, "Initial discovery of Triatoma costalimai naturally infected with Trypanosoma cruzi: study of the biological aspects of an isolated sample," Memorias do Instituto Oswaldo Cruz, vol. 76, no. 1, pp. 61-69, 1981.

[103] D. A. Mello, "Roedores, marsupiais e triatomineos silvestres capturados no municipio de Mambaí-Goiás. Infecção natural pelo Trypanosoma cruzi," Revista de Saude Publica, vol. 16, no. 5, pp. 282-291, 1982.

[104] E. S. Lorosa, R. E. Andrade, S. M. Santos, C. A. Pereira, M. C. Vinhaes, and J. Jurberg, "Estudo da infecção natural e fontes alimentares de Triatoma costalimai Verano \& Galvão, 1959, Rhodnius neglectus Lent, 1954 e Psammolestes tertius Lent \& Jurberg, 1965 do estado de Goiás, Brasil, através da técnica de precipitina," Entomologia y Vectores, vol. 6, no. 4, pp. 405414, 1999.

[105] J. Costa, C. E. Almeida, E. M. Dotson et al., "The epidemiologic importance of Triatoma brasiliensis as a Chagas disease vector in Brazil: a revision of domiciliary captures during 1993-1999," Memorias do Instituto Oswaldo Cruz, vol. 98, no. 4, pp. 443-449, 2003.

[106] J. Costa, J. Ribeiro De Almeida, C. Britto, R. Duarte, V. Marchon-Silva, and R. D. S. Pacheco, "Ecotopes, natural infection and trophic resources of Triatoma brasiliensis (Hemiptera, Reduviidae, Triatominae)," Memorias do Instituto Oswaldo Cruz, vol. 93, no. 1, pp. 7-13, 1998.

[107] F. A. Monteiro, M. J. Donnelly, C. B. Beard, and J. Costa, "Nested clade and phylogeographic analyses of the Chagas disease vector Triatoma brasiliensis in northeast Brazil," Molecular Phylogenetics and Evolution, vol. 32, no. 1, pp. 46$56,2004$.

[108] J. Costa, A. T. Peterson, and J. P. Dujardin, "Morphological evidence suggests homoploid hybridization as a possible mode of speciation in the Triatominae (Hemiptera, Heteroptera, Reduviidae)," Infection, Genetics and Evolution, vol. 9, no. 2, pp. 263-270, 2009.

[109] C. E. Almeida, E. Folly-Ramos, A. T. Peterson et al., "Could the bug Triatoma sherlocki be vectoring chagas disease in small mining communities in Bahia, Brazil?" Medical and Veterinary Entomology, vol. 23, no. 4, pp. 410-417, 2009.

[110] S. P. Carneiro Freitas, E. S. Lorosa, D. C. Silva Rodrigues, A. L. Carneiro Freitas, and T. C. Monte Gonçalves, "Feeding patterns of Triatoma pseudomaculata in the state of Ceará, Brazil," Revista de Saude Publica, vol. 39, no. 1, pp. 27-32, 2005.

[111] G. F. Machado De Assis, B. V. D. M. Azeredo, D. Gorla, L. Diotaiuti, and M. De Lana, "Entomological surveillance of Chagas disease in Berilo municipality, Jequitinhonha Valley, State of Minas Gerais, Brazil," Revista da Sociedade Brasileira de Medicina Tropical, vol. 42, no. 6, pp. 615-621, 2009.

[112] G. F.M. De Assis, B. V.D.M. Azeredo, A. L.C. De La Fuente, L. Diotaiuti, and M. De Lana, "Domiciliation of Triatoma pseudomaculata (Corrêa e Espínola 1964) in the Jequitinhonha Valley, State of Minas Gerais," Revista da Sociedade Brasileira de Medicina Tropical, vol. 40, no. 4, pp. 391-396, 2007.

[113] A. G. Dias-Lima, D. Menezes, I. Sherlock, and F. Noireau, "Wild habitat and related fauna of Panstrongylus lutzi (Reduviidae, Triatominae)," Journal of Medical Entomology, vol. 40, no. 6, pp. 989-990, 2003.

[114] A. S. Pinto and D. N. Bento, "The palm tree Copernicia cerifera (carnaúba) as an ecotope of Rhodnius nasutus in rural areas of the state of Piauí, northeastern Brazil," Revista da Sociedade Brasileira de Medicina Tropical, vol. 19, no. 4, pp. 243-245, 1986.
[115] M. M. Lima and O. Sarquis, "Is Rhodnius nasutus (Hemiptera; Reduviidae) changing its habitat as a consequence of human activity?" Parasitology Research, vol. 102, no. 4, pp. 797-800, 2008.

[116] O. Sarquis, J. Borges-Pereira, J. R. Mac Cord, T. F. Gomes, P. H. Cabello, and M. M. Lima, "Epidemiology of Chagas disease in Jaguaruana, Ceará, Brazil. I. Presence of triatomines and index of Trypanosoma cruzi infection in four localities of a rural area," Memorias do Instituto Oswaldo Cruz, vol. 99, no. 3, pp. 263-270, 2004.

[117] M. Steindel, L. Kramer Pacheco, D. Scholl et al., "Characterization of Trypanosoma cruzi isolated from humans, vectors, and animal reservoirs following an outbreak of acute human Chagas disease in santa Catarina state, Brazil," Diagnostic Microbiology and Infectious Disease, vol. 60, no. 1, pp. 25-32, 2008.

[118] K. S. O. Santana, M. E. Bavia, A. D. Lima et al., "Patial distribution of triatomines (Reduviidae: Triatominae) in urban areas of the city of Salvador, Bahia, Brazil," Geospatial Health, vol. 5, no. 2, pp. 199-203, 2011.

[119] F. Abad-Franch and F. A. Monteiro, "Biogeography and evolution of Amazonian triatomines (Heteroptera: Reduviidae): implications for Chagas disease surveillance in humid forest ecoregions," Memorias do Instituto Oswaldo Cruz, vol. 102, no. 1, pp. 57-69, 2007.

[120] M. A. Miles, J. R. Arias, and A. A. de Souza, "Chagas' disease in the Amazon basin: V. Periurban palms as habitats of Rhodnius robustus and Rhodnius pictipes-triatomine vectors of Chagas' disease," Memorias do Instituto Oswaldo Cruz, vol. 78, no. 4, pp. 391-398, 1983.

[121] H. M. Aguilar, F. Abad-Franch, J. C. P. Dias, A. C. V. Junqueira, and J. R. Coura, "Chagas disease in the Amazon Region," Memorias do Instituto Oswaldo Cruz, vol. 102, no. 1, pp. 47-55, 2007.

[122] S. A. D. S. Valente, V. da Costa Valente, A. Y. das Neves Pinto et al., "Analysis of an acute Chagas disease outbreak in the Brazilian Amazon: human cases, triatomines, reservoir mammals and parasites," Transactions of the Royal Society of Tropical Medicine and Hygiene, vol. 103, no. 3, pp. 291-297, 2009.

[123] R. Salvatella, R. Rosa, Y. Basmadjian et al., "Ecology of Triatoma rubrovaria (Hemiptera, Triatominae) in wild and peridomestic environments of Uruguay," Memórias do Instituto Oswaldo Cruz, vol. 90, no. 3, pp. 325-328, 1995.

[124] C. E. Almeida, M. C. Vinhaes, J. R. Almeida, A. C. Silveira, and J. Costa, "Monitoring the domiciliary and peridomiciliary invasion process of Triatoma rubrovaria in the State of Rio Grande do Sul, Brazil," Memorias do Instituto Oswaldo Cruz, vol. 95, no. 6, pp. 761-768, 2000.

[125] J. C. P. Dias, "Southern Cone Initiative for the elimination of domestic populations of Triatoma infestans and the interruption of transfusional Chagas disease. Historical aspects, present situation, and perspectives," Memorias do Instituto Oswaldo Cruz, vol. 102, supplement 2, pp. 11-18, 2007. 


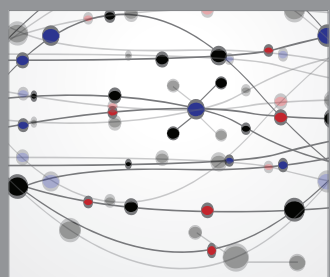

The Scientific World Journal
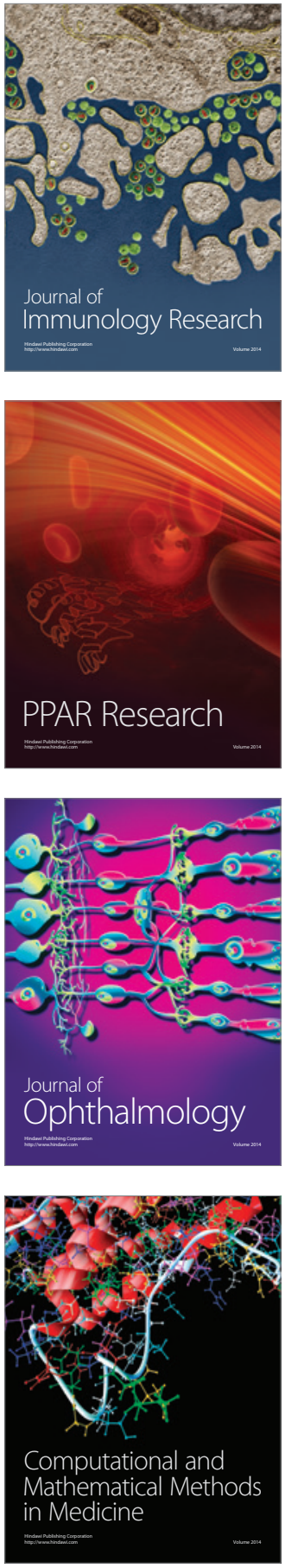

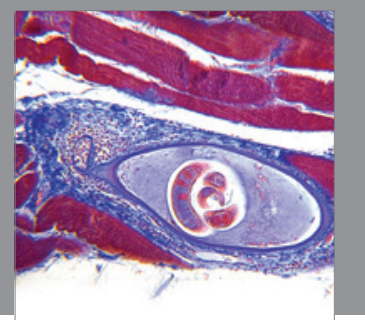

Gastroenterology

Research and Practice
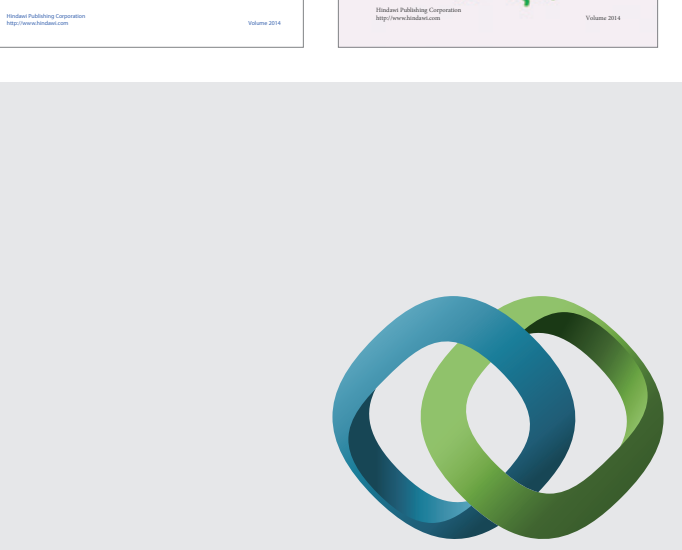

\section{Hindawi}

Submit your manuscripts at

http://www.hindawi.com
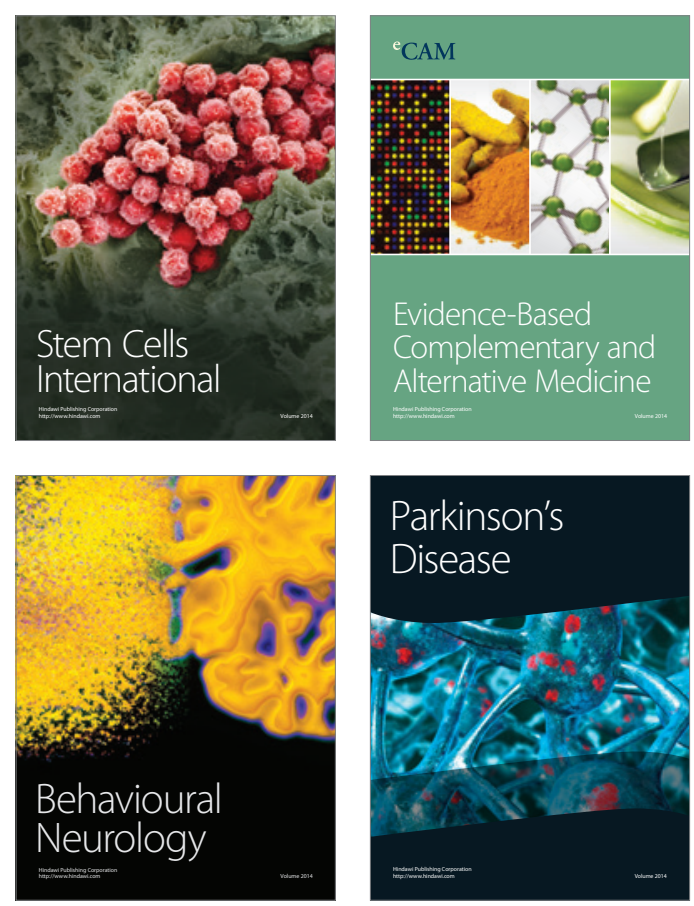

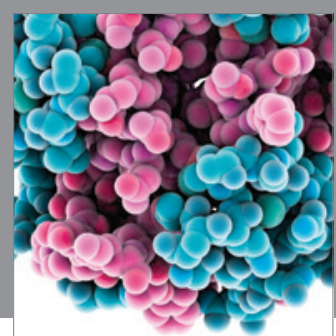

Journal of
Diabetes Research

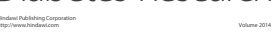

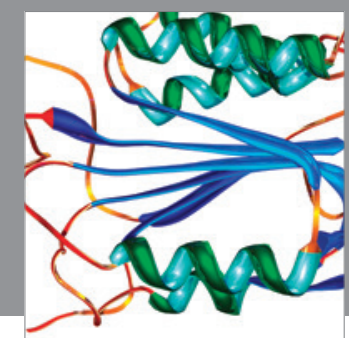

Disease Markers
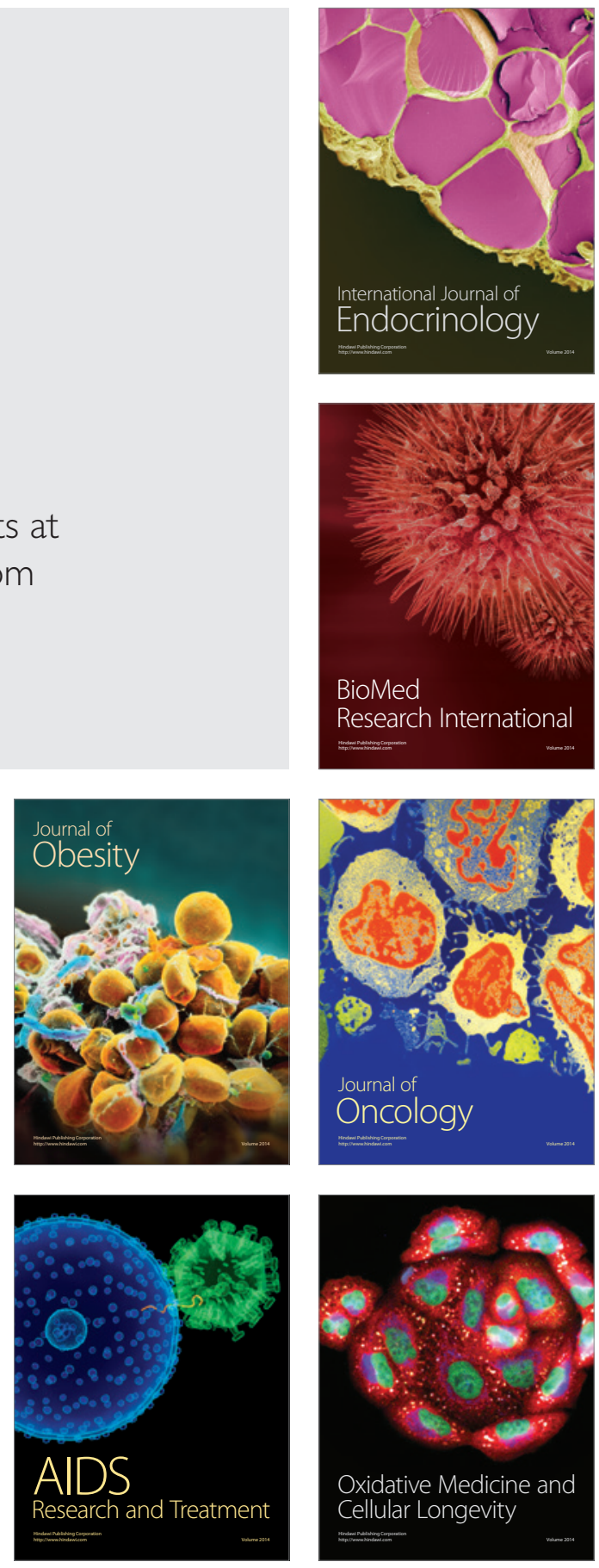